\title{
Volatility and hygroscopicity of aging secondary organic aerosol in a smog chamber
}

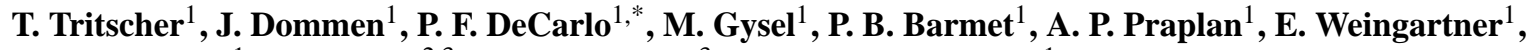 \\ A. S. H. Prévôt ${ }^{1}$, I. Riipinen ${ }^{2,3}$, N. M. Donahue ${ }^{3}$, and U. Baltensperger ${ }^{1}$ \\ ${ }^{1}$ Laboratory of Atmospheric Chemistry, Paul Scherrer Institut, Villigen, Switzerland \\ ${ }^{2}$ Department of Physics, University of Helsinki, Helsinki, Finland \\ ${ }^{3}$ Department of Chemical Engineering, Carnegie Mellon University, Pittsburgh, PA, USA \\ *now at: Department of Civil, Architectural and Environmental Engineering, Drexel University, Philadelphia, PA, USA
}

Received: 24 February 2011 - Published in Atmos. Chem. Phys. Discuss.: 3 March 2011

Revised: 27 October 2011 - Accepted: 2 November 2011 - Published: 18 November 2011

\begin{abstract}
The evolution of secondary organic aerosols (SOA) during (photo-)chemical aging processes was investigated in a smog chamber. Fresh SOA from ozonolysis of 10 to $40 \mathrm{ppb} \alpha$-pinene was formed followed by aging with $\mathrm{OH}$ radicals. The particles' volatility and hygroscopicity (expressed as volume fraction remaining (VFR) and hygroscopicity parameter $\kappa$ ) were measured in parallel with a volatility and hygroscopicity tandem differential mobility analyzer (V/H-TDMA). An aerosol mass spectrometer (AMS) was used for the chemical characterization of the aerosol. These measurements were used as sensitive parameters to reveal the mechanisms possibly responsible for the changes in the SOA composition during aging. A change of VFR and/or $\kappa$ during processing of atmospheric aerosols may occur either by addition of SOA mass (by condensation) or by a change of SOA composition leading to different aerosol properties. The latter may occur either by heterogeneous reactions on the surface of the SOA particles, by condensed phase reactions like oligomerization or by an evaporation - gas-phase oxidation - recondensation cycle. The condensation mechanism showed to be dominant when there is a substantial change in the aerosol mass by addition of new molecules to the aerosol phase with time. Experiments could be divided into four periods based on the temporal evolution (qualitative changes) of VFR, $\kappa$ and organic mass: $\mathrm{O}_{3}$ induced condensation, ripening, and $\mathrm{OH}$ induced chemical aging first with substantial mass gain and then without significant mass gain.
\end{abstract}

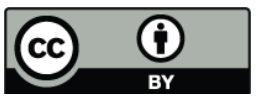

Correspondence to: E. Weingartner (ernest.weingartner@psi.ch)
During the $\mathrm{O}_{3}$ induced condensation the particles' volatility decreased (increasing VFR) while the hygroscopicity increased. Thereafter, in the course of ripening volatility continued to decrease, but hygroscopicity stayed roughly constant. After exposing the $\mathrm{SOA}$ to $\mathrm{OH}$ radicals an $\mathrm{OH}$ induced chemical aging with substantial mass gain started resulting in the production of at least $50 \%$ more SOA mass. This new SOA mass was highly volatile and oxidized. This period was then followed by further $\mathrm{OH}$ induced chemical aging without significant mass gain leading to a decrease of volatility while hygroscopicity and SOA mass stayed roughly constant.

\section{Introduction}

Secondary organic aerosols (SOA) are a major constituent of the atmospheric particulate matter and originate from chemical transformation of primary volatile organic compounds (VOC) to lower volatility products that partition into the condensed phase. Many studies have already been performed on SOA formation and properties (see e.g. references in Hallquist et al. 2009). One of the major challenges for SOA studies is the multi-component composition of SOA with only few known substances among thousands of unknown species. Field measurements show changing SOA properties with oxidative aging, but detailed studies of these processes under ambient conditions in the lab are challenging and thus scarce (Rudich et al., 2007).

State-of-the-art chemical transport and box models cannot reproduce the measured ambient organic aerosol concentrations (i.e. directly emitted primary organic aerosol (POA) and

Published by Copernicus Publications on behalf of the European Geosciences Union. 
Table 1. The three main chemical processes and their expected influence on volatility and hygroscopicity, and on additional parameters: van't Hoff factor $i_{\mathrm{S}}$; the ratio of density to molar weight of solute, $\rho_{\mathrm{S}} / M_{\mathrm{S}}$. Symbols represent: + expected to increase, - expected to decrease, $\sim$ only minor change expected. For hygroscopicity $(\kappa)$ see also Eq. (1). Note that if the chemical processes result in a substantial aerosol mass gain, then the resulting changes of particle volatility and hygroscopicity are determined by the relative difference between the properties of the previous and added SOA mass, and consequently the trends indicated in Table 1 are not applicable.

\begin{tabular}{lccc}
\hline & functionalization & oligomerization & fragmentation \\
\hline volatility & - & - & $+/ \sim$ \\
VFR & + & + & $-/ \sim$ \\
\hline$i_{\mathrm{S}}$ & $+/ \sim$ & $\sim$ & $\sim$ \\
$\rho_{\mathrm{S}} / M_{\mathrm{S}}$ & $\sim$ & - & + \\
hygroscopicity $(\kappa)$ & $+/ \sim$ & - & + \\
\hline
\end{tabular}

SOA formed from various precursors) with currently known chemical and physical mechanisms (Volkamer et al., 2006; Hodzic et al., 2010). One important challenge in modeling SOA mass in the atmosphere or under laboratory conditions is the correct implementation of the gas-particle interactions such as the partitioning effect (Pankow, 1994a,b). Recently the volatility basis set (VBS) approach was introduced (Donahue et al., 2006; Robinson et al., 2007; Jimenez et al., 2009), lumping the various organic compounds together according to their effective saturation mass concentration $\left(\mathrm{C}^{*}\right)$ in order to describe the semi-volatile nature of the SOA particles including their gas-particle partitioning behavior. $\mathrm{C}^{*}$ is the mass equivalent of the saturation vapor pressure, which controls volatility. Volatility is a key property of the organic components of the gas and particulate phase and it determines the SOA formation and the partitioning between the phases.

Laboratory experiments e.g. in chambers span a wide range of semi-volatile oxygenated organic aerosol (SVOOA), but low-volatility oxygenated organic aerosol (LVOOA), as found in ambient measurements of aged air masses, is still difficult to study and reproduce under laboratory conditions (Jimenez et al., 2009). The atomic oxygen to carbon ratio (O:C ratio) of SOA can be used to roughly split the mass to SV-OOA and LV-OOA components. It also allows the classification of organics within the VBS framework.

Formation of SOA involves oxidation of semi-volatile vapors from primary emissions to less volatile species which partition into the organic aerosol. In a simplified picture we start with a pure volatile hydrocarbon species which is oxidized to different first generation oxidized products of a large range of volatilities. From the low volatility species a secondary organic aerosol is formed while the volatile and semi-volatile species form a large pool of organic mass in the gas phase in equilibrium with the particle phase. This aerosol can be further processed, which is called aging; this includes various processes changing the properties of the particles (Qi et al., 2010). Most of the oxidation will take place in the gas phase and either generates more SOA via further func- tionalization (adding more oxygen to the carbon backbone) or fragmentation upon oxidation of the semi-volatile gases. Heterogeneous oxidation is much slower than gas phase oxidation due to mass-transfer limitations. Heterogeneous reactions include functionalization and fragmentation as well as some transformation reactions of functional groups (alcohol to carbonyl). Additional reactions in the condensed phase such as oligomerization have also been observed (Kalberer et al., 2004). Functionalization and fragmentation lead to an increase in the $\mathrm{O}: \mathrm{C}$ ratio while oligomerization may increase or decrease it depending on the process (Reinhardt et al., 2007). Functionalization always decreases volatility while fragmentation forms species in a wide range of volatilities albeit mostly at lower volatilities. Oligomerization converts monomers to larger, less volatile compounds. The expected effects of the three main processes on particle volatility are summarized in Table 1.

Atmospheric aerosols are composed of inorganic and organic substances, including SOA components. They have an influence on global climate via the direct aerosol effect by scattering sunlight and via the indirect aerosol effect by changing cloud properties and characteristics (Lohmann and Feichter, 2005). Hygroscopicity, the degree of water uptake by particles, is an important parameter for both effects and has been studied for different SOA types (Baltensperger et al., 2005; Varutbangkul et al., 2006; Prenni et al., 2007; Duplissy et al., 2008; Juranyi et al., 2009; Qi et al., 2010). A positive correlation between hygroscopicity and $\mathrm{O}: \mathrm{C}$ ratio has been shown recently (Jimenez et al., 2009; Chang et al., 2010; Massoli et al., 2010; Duplissy et al., 2011). The following equation for the hygroscopicity parameter $\kappa$ can be derived from Petters and Kreidenweis (2007) to represent the hygroscopicity of an aerosol:

$\kappa=v_{\mathrm{w}} \times \frac{\rho_{\mathrm{s}}}{M_{\mathrm{s}}} \times i_{\mathrm{s}}$

where $v_{\mathrm{w}}$ is the partial molar volume of water, $M_{\mathrm{s}}, \rho_{\mathrm{S}}$ and $i_{\mathrm{S}}$ the molar mass, density and effective van't Hoff factor of the solute, respectively. $v_{\mathrm{w}}$ is in good approximation constant 


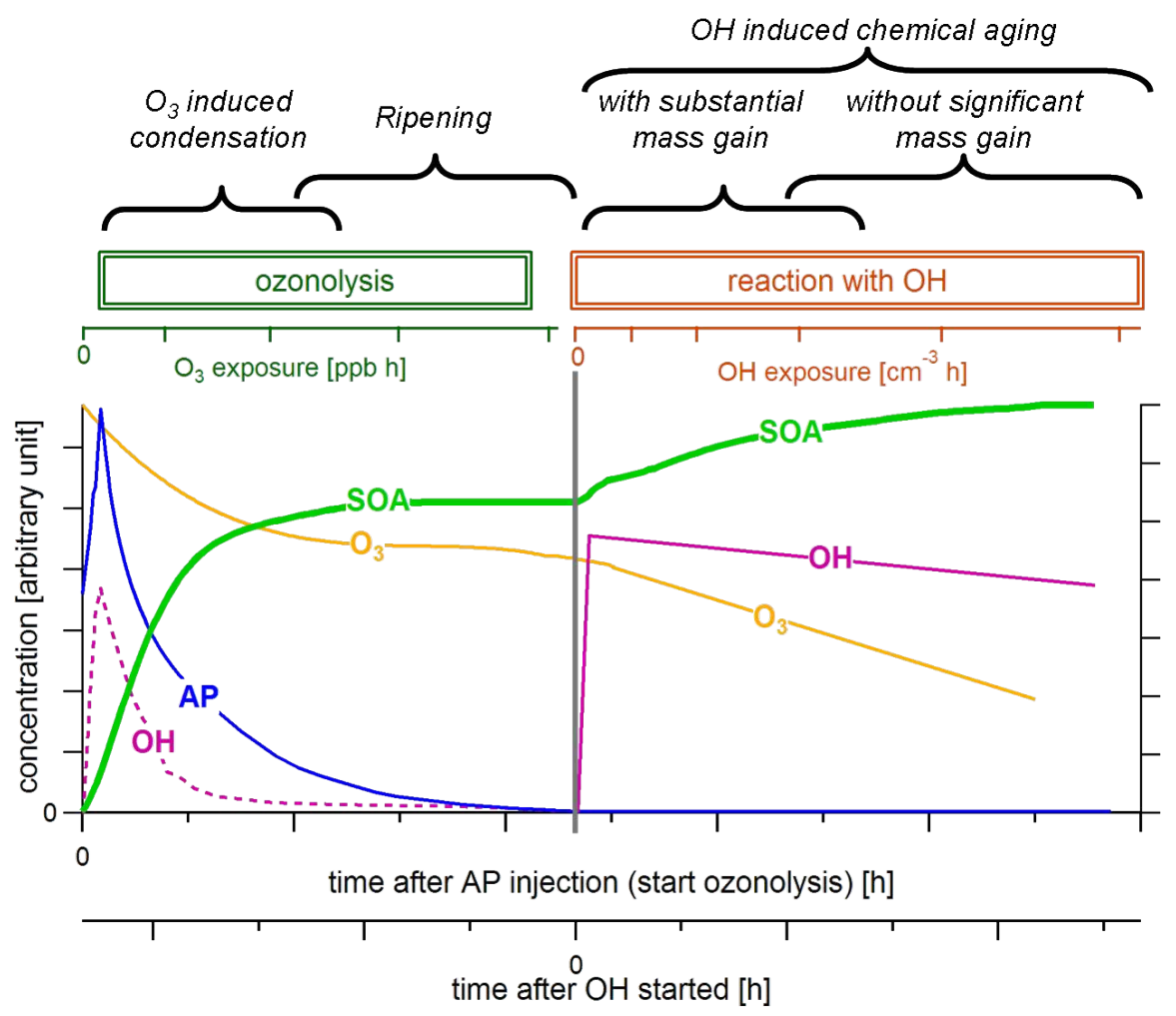

Fig. 1. Schematic of the main features of the smog chamber experiments during MUCHACHAS. Formation of secondary organic aerosol (SOA) mass (wall-loss corrected) from the volatile organic precursor $\alpha$-pinene (AP) takes place during the first part in dark with ozone $\left(\mathrm{O}_{3}\right)$. The ozonolysis is followed by $\mathrm{OH}$ chemistry to age the SOA. The data can be plotted against several time axes as "time after AP injection was started" and "time after the $\mathrm{OH}$ reaction started" or against a "chemical clock" as $\mathrm{O}_{3}$ exposure and OH exposure. During ozonolysis and reaction with $\mathrm{OH}$ the four different periods of our experiments are indicated above the figure: $\mathrm{O}_{3}$ induced condensation, ripening, $\mathrm{OH}$ induced chemical aging with substantial mass gain, and $\mathrm{OH}$ induced chemical aging without significant mass gain.

across the water activity range of interest. This leaves $i_{\mathrm{S}}$ and $\rho_{\mathrm{S}} / M_{\mathrm{S}}$ as the two key factors determining particle hygroscopicity $(\kappa)$. The expected effect of the three main chemical processes on $i_{\mathrm{S}}$ and $\rho_{\mathrm{S}} / M_{\mathrm{S}}$ and thus $\kappa$ is also summarized in Table 1.

Functionalization typically increases $i_{\mathrm{S}}$ slightly due to positive interactions between polar functional groups and water (Petters et al., 2009). Additional dissociation effects would also increase $i_{\mathrm{s}}$, though the degree of dissociation of carboxyl and hydroxyl groups is likely very small. Only a small increase, if at all, is expected for $M_{\mathrm{S}}$ and $\rho_{\mathrm{S}}$, and thus changes of $\rho_{\mathrm{S}} / M_{\mathrm{S}}$ will be small. $\kappa$ is thus expected to increase slightly under the influence of functionalization.

Oligomerization strongly increases $M_{\mathrm{s}}$ with little effect on $\rho_{\mathrm{S}}$, resulting in a decrease of $\rho_{\mathrm{S}} / M_{\mathrm{S}}$. Only small changes are expected for $i_{\mathrm{s}}$. Overall a decrease of $\kappa$ is expected under the influence of oligomerization, though the effect becomes smaller with increasing $M_{\mathrm{S}}$ (Petters et al., 2006).

Fragmentation strongly decreases $M_{\mathrm{s}}$ with little effect on $\rho_{\mathrm{S}}$, resulting in an increase of $\rho_{\mathrm{S}} / M_{\mathrm{s}}$. Only small changes are expected for $i_{\mathrm{S}}$. Overall an increase of $\kappa$ is expected under the influence of fragmentation.
Equation (1) describes the hygroscopicity of completely dissolved solutes. Particle hygroscopicity would be reduced if the SOA was only partially soluble. Functionalization and fragmentation increase the solubility, while oligomerization decreases the solubility. The potential effects of functionalization, fragmentation or oligomerization on particle hygroscopicity caused by solubility changes have equal sign as the effects of changes of $i_{\mathrm{s}}, \rho_{\mathrm{S}}$ and $M_{\mathrm{S}}$. Thus the summary of the effect of the three main chemical reactions on particle hygroscopicity as presented in Table 1 remains valid also under the influence of solubility limitations.

The chemical and physical characterization of SOA is often discussed separately (Hallquist et al., 2009). So far it is not clear how oxidation (aging) changes the amount and properties of SOA. Here we investigate the aerosol physical properties of SOA volatility and hygroscopicity as a function of the oxidant exposure under controlled conditions. Comparing trends of volatility and hygroscopicity may shed light on the dominant processes in the course of SOA aging.

These measurements were conducted at the Paul Scherrer Institute (PSI) smog chamber within the scope of the MUCHACHAS (Multiple Chamber Aerosol Chemistry and 
Aging Studies) campaigns. MUCHACHAS took place in several chambers in Europe and the US with different points of emphasis for a similar set of experiments. The main emphasis for the MUCHACHAS experiments at the PSI smog chamber was the aging of $\alpha$-pinene (AP) SOA with $\mathrm{OH}$ under dark and light conditions.

The typical design of the MUCHACHAS experiments is shown as schematic in Fig. 1. The precursor in all experiments described here was AP. The concept was to first form SOA from ozonolysis, allow it to stabilize after nearly all the precursor was consumed, and then to expose the firstgeneration SOA and partially oxidized gas-phase species to $\mathrm{OH}$ radicals in order to observe changes caused by $\mathrm{OH}$ aging.

A change of the VFR and/or the $\kappa$ value during processing of atmospheric aerosols may occur either by addition of SOA mass (by condensation) or by an exchange of molecules in the SOA by other molecules with different properties. The former process increases the SOA mass by definition, while the latter keeps the SOA mass roughly constant and may occur either by heterogeneous reactions on the surface of the SOA particles, condensed phase reactions like oligomerization or by an evaporation - gas-phase oxidation - recondensation cycle. Thus, when there is a substantial change in the aerosol mass by addition of new molecules to the aerosol phase with time, the condensation mechanism may be assumed to be dominant, while, when the mass stays roughly constant the exchange mechanism is the likely dominant process. In the light of this, we assign the following four dominating mechanisms to four different periods of our experiments (see Fig. 1): $\mathrm{O}_{3}$ induced condensation; ripening; $\mathrm{OH}$ induced chemical aging with substantial mass gain; $\mathrm{OH}$ induced chemical aging without significant mass gain. In the condensation periods, the physical (VFR, $\kappa$ ) and chemical (O:C ratio) properties are believed to mainly vary as a result of the additional condensing material, in contrast to chemical transformation of the SOA during periods without significant change of the mass.

\section{The experimental setup}

\subsection{Smog chamber and associated instruments}

The air in the $27-\mathrm{m}^{3}$ Teflon bag in a temperature controlled chamber with four filtered xenon lamps providing quasisolar illumination is monitored by several gas and aerosol phase instruments described in detail in Paulsen et al. (2005). Here we mention the main instruments relevant for this paper and the experimental procedure. The particles volatility and hygroscopicity were characterized with a volatility and hygroscopicity tandem differential mobility analyzer $(\mathrm{V} / \mathrm{H}-$ TDMA, see Sect. 2.2). The aerosol particle number size distribution (diameter $D=20-800 \mathrm{~nm}$ ) and chemical composition were measured with a scanning mobility particle sizer (SMPS) and an Aerodyne high resolution time of flight aerosol mass spectrometer (AMS). The AMS detects inorganic and organic aerosol species quantitatively and is described elsewhere in detail (DeCarlo et al., 2006). It allows the chemical quantification and characterization of several types of fragments of the SOA with a time resolution of a few seconds (e.g. Alfarra et al. 2006). The organic aerosol mass measurement from the AMS was wall-loss corrected to account for the losses to the chamber walls. Assuming that the wall loss rate is first order and independent of size we used an exponential fit asymptotically decreasing to zero to correct for the losses (Pathak et al., 2007). In the following the terms "organic aerosol mass" or "SOA mass" always relate to wall-loss corrected organic particulate mass. A very useful parameter derived from AMS data is the oxygen to carbon ratio (O:C ratio) (Aiken et al., 2007, 2008), which was linked to the hygroscopicity properties of the aerosol (Duplissy et al., 2011).

The gas-phase instruments include $\mathrm{NO}_{\mathrm{x}}$ monitors (Monitor Labs 9841A, Thermo Environmental Instruments 42C) and ozone monitors (Monitor Labs 8810, Environics S300). A proton transfer reaction mass spectrometer (PTR-MS) from IONICON was deployed as well. The high sensitivity PTR-MS (Lindinger et al., 1998) is able to detect VOCs in real-time with a very low detection limit (ppt level). From the measurement of the precursor $\alpha$-pinene we calculated "AP reacted". However, after injection of AP into the ozone $\left(\mathrm{O}_{3}\right)$ containing chamber the initial concentration was not directly measured because AP needs to mix first and already starts to react with $\mathrm{O}_{3}$. It was therefore determined from fitting the AP concentration trend back to the injection time.

\subsection{V/H-TDMA instrument}

We built a new V/H-TDMA instrument which is described and characterized in more detail here. The tandem differential mobility analyzer (TDMA) technique (Rader and McMurry, 1986) is a common technique to characterize aerosol properties. The H-TDMA technique is well established and a suitable method to measure the hygroscopicity of submicrometer aerosol (Swietlicki et al., 2008). Our combined volatility and hygroscopicity tandem differential mobility analyzer (V/H-TDMA) runs volatility and hygroscopicity scans in parallel (Fig. 2). The aerosol is conditioned before entering the first differential mobility analyzer (DMA1) by passing through a diffusion dryer and a $\mathrm{Kr}-85$ bipolar charger to bring the particles into charge equilibrium. All DMAs are situated in a temperature controlled, well insulated housing at $20^{\circ} \mathrm{C}$. DMA1 size selects a dry $(\mathrm{RH}<15 \%)$, quasimonodisperse aerosol, which is split into a heater and a humidifier flow (0.3 $\mathrm{L} \mathrm{min}^{-1}$ each). Two additional DMAs scan the humidified or heated particles (DMA2 and DMA3, respectively) which are then counted with the condensation particle counter for hygroscopicity $\left(\mathrm{CPC}_{\mathrm{H}}\right)$ and for volatility $\left(\mathrm{CPC}_{\mathrm{V}}\right)$, respectively. 


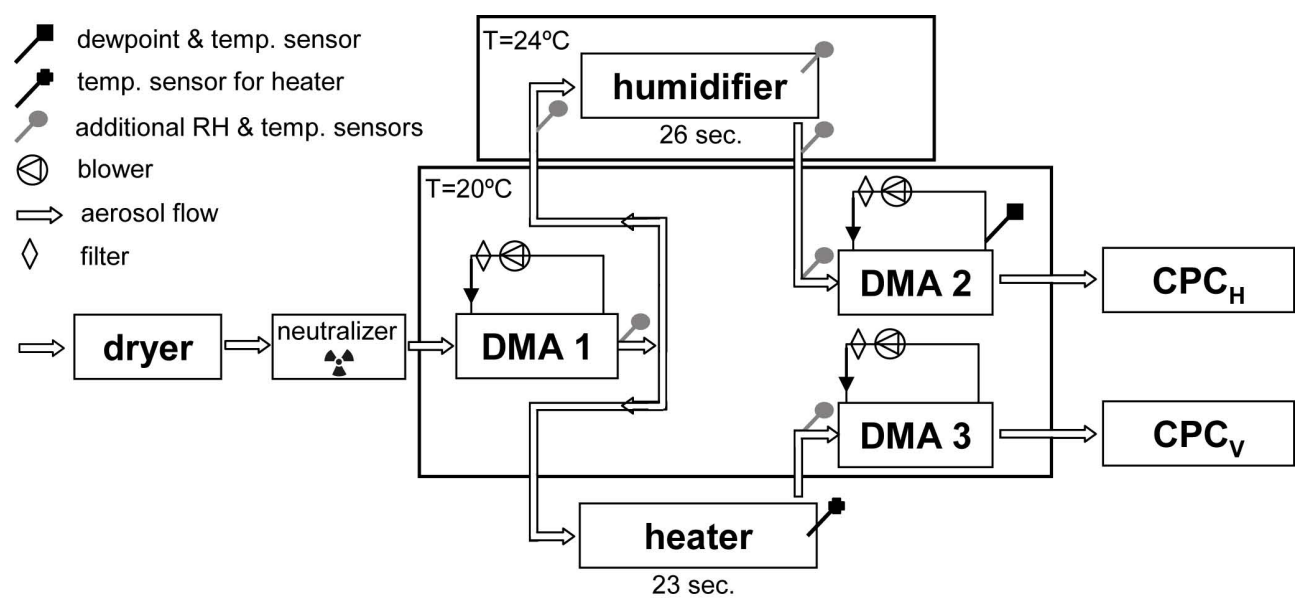

Fig. 2. Schematic of the combined volatility and hygroscopicity tandem differential mobility analyzer (V/H-TDMA) setup with the main instrument parts and sensors. The reference RH of the humidified branch is calculated from the dewpoint and temperature measured by a dew point mirror at the excess air outlet DMA2. The reference temperature for the V-branch is just before the outlet of the heater. The given residence times are measured between outlet of DMA1 and DMA2 or DMA3, respectively.

Two additional DMAs scan the humidified or heated particles (DMA2 and DMA3, respectively) which are then counted with the condensation particle counter for hygroscopicity $\left(\mathrm{CPC}_{\mathrm{H}}\right)$ and for volatility $\left(\mathrm{CPC}_{\mathrm{V}}\right)$, respectively.

The H-TDMA part is based on the design of a previous instrument (Duplissy et al., 2008, 2009). The individual sheath air flows are operated in closed loops and the flows are maintained with blowers (Fig. 2), which are controlled by laminar flow elements combined with differential pressure sensors and proportional-integral-derivative (PID) controllers. A separate humidifier loop with bubbler (not shown in Fig. 2) supplies the humidifier with humid air. The humidifier section is situated in a second, temperature controlled housing at $24{ }^{\circ} \mathrm{C}$. The aerosol can be humidified up to a controlled relative humidity (RH) of $97 \pm 1 \%$ with a residence time of $\sim 26 \mathrm{~s}$ (between DMA1 and DMA2).

Measurement of the deliquescence RH of ammonium sulfate (AS) and other salts e.g. sodium chloride $(\mathrm{NaCl})$ are used for the calibration of the dew point mirror (see Fig. 2) to assure accurate RH measurement. The correct absolute sizing of the DMAs is periodically checked with polystyrene latex (PSL) spheres having dry diameters $D_{0}$ between 100 and $350 \mathrm{~nm}$. The correct sizing of the DMAs with respect to each other is frequently checked by conducting a series of measurements without heating and humidifying. This relative calibration of DMA1 with DMA2/DMA3 is important to detect small instrumental drifts which would affect the precision of the growth factor measurements (the error in $D / D_{0}$ is typically $<1 \%$ ).

The heater in the V-TDMA part is custom-built and consists of an inner linear brass tube $(70 \times 2.2 \mathrm{~cm})$ surrounded by capillary tubes containing a heating wire. The small space between these capillary tubes allows for a rapid cooling with pressurized air. The temperature sensor in the center of the inner tube (see Fig. 2) controls the heater temperature $(T)$ in a range from $25-200^{\circ} \mathrm{C}\left( \pm 2{ }^{\circ} \mathrm{C}\right)$. Modeling of the temperatures and flow streamlines inside the heater suggests a laminar flow and a homogeneous temperature distribution after at most $15 \mathrm{~cm}$ from the inlet. The calculated plug flow residence time (RT) in the heater for $25-200^{\circ} \mathrm{C}$ is $24.4-15.4 \mathrm{~s}$ at a constant aerosol flow of $0.6 \mathrm{~L} \mathrm{~min}^{-1}$. The aerosol flow is diluted with filtered, pure air before $\left(0.3 \mathrm{~L} \mathrm{~min}^{-1}\right)$ and after the heater $\left(0.4 \mathrm{~L} \mathrm{~min}^{-1}\right)$ to maintain correct aerosol flows in all parts of the instrument. Measurements of the aerosol particles' average "traveling time" from the outlet of DMA1 to the inlet of DMA3 (including heater and tubing) was found to be $23 \pm 2 \mathrm{~s}$ at $30^{\circ} \mathrm{C}$. The RT is longer compared to other heaters employed in TDMAs (Paulsen et al., 2005; Jonsson et al., 2007; Villani et al., 2007) and thermodenuder (Burtscher et al., 2001; Wehner et al., 2002). This typically results in a lower remaining aerosol volume at a specific temperature. As particle concentrations are rather small, a denuder is not needed in our system because the inner surface of the heater offers much larger surface for the vapors to condense than the aerosols. Nucleation, an indicator for re-condensation of vapors, was not observed in the V-TDMA.

In general the parameters obtained from the TDMA are the growth factor $\mathrm{GF}(\mathrm{RH})$, and shrinking factor $\mathrm{SF}(T)$ defined as the ratio of humidified diameter $D(\mathrm{RH})$, or heated diameter $D(T)$ and initial dry and non-heated diameter $\left(D_{0}\right)$, respectively:

$$
\begin{aligned}
& \mathrm{GF}(\mathrm{RH})=\frac{D(\mathrm{RH})}{D_{0}} \\
& \mathrm{SF}(T)=\frac{D(T)}{D_{0}}
\end{aligned}
$$




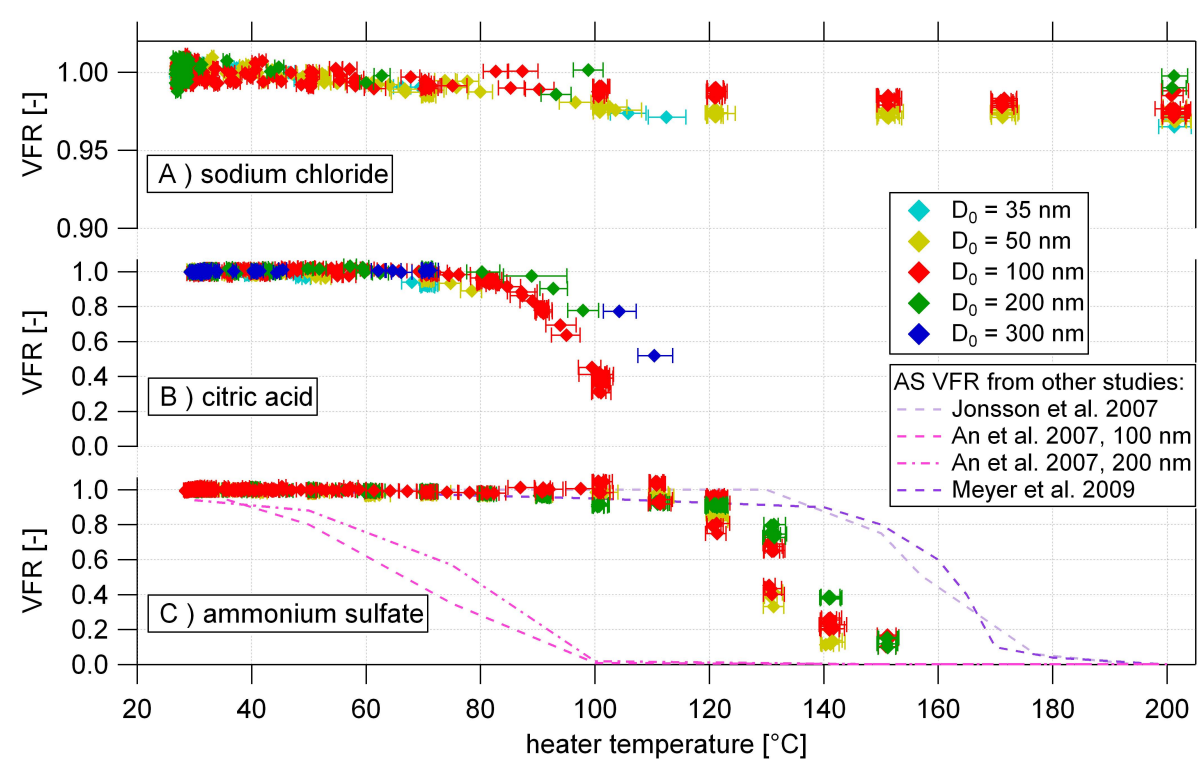

Fig. 3. Thermograms, normalized volume fraction remaining (VFR) plotted against the measured heater temperature, for sodium chloride $(\mathrm{NaCl})$ in panel (a), citric acid in panel (b) and ammonium sulfate (AS) in panel (c) as retrieved from the V-TDMA measurements. Different dry diameters $\left(D_{0}\right)$ are distinguished by color and the error bars represent the minimal and maximal temperature during a scan. In panel (c) thermograms for AS from other studies were added for comparison (dashed lines).

The raw growth or shrinking factor distributions measured by the H- and V-part are analyzed using the TDMAinv approach (Gysel et al., 2009) in order to obtain inverted and calibrated probability density functions (PDF). Details on this data analysis procedure and especially on the used TDMAinv approach are found in Gysel et al. (2009). In the following the hygroscopic growth factor (GF) always refers to the number weighted mean GF (1st moment) of the inverted GF-PDF, and the shrinking factor (SF) to the volume weighted mean SF (3rd moment) of the inverted SF-PDF. Instead of SF the volume fraction remaining (VFR), defined as VFR $=\mathrm{SF}^{3}$, is chosen to present the volatility data.

In this study the H-TDMA was typically operated at a constant high RH of $95 \%$. The GFs measured in the RH range between $93-97 \%$ were recalculated to $95.0 \%$ RH following Gysel et al. (2009), using a single-parameter growth curve parametrization for correcting small RH differences. The used RH correction in a small band of $\pm 2 \% \mathrm{RH}$ minimizes systematic biases when reporting temporal evolution of GF at constant target RH. This is especially of importance when overall changes in the GF evolution are not large. The VTDMA heater was running mainly at $70^{\circ} \mathrm{C}$ (with a plug flow RT of $21 \mathrm{~s}$ ) and only data in the range $T=68-72^{\circ} \mathrm{C}$ were considered in the analysis. We minimized pyrolysis in the heater by using a low thermodenuder temperature with a relatively long residence time. During a few experiments the heater temperature was varied (from 25 to $200^{\circ} \mathrm{C}$ ) to measure the VFR as a function of temperature, resulting in a thermogram plot.
Typically particles are small in the beginning of an SOA experiment, but grow very rapidly during the ozonolysis and stabilize at a diameter of a few hundred nanometers. Several $D_{0}$ in the diameter range across the mode of the size distribution were selected for the H-TDMA and V-TDMA measurements at a time and the diameter range covered was gradually increased to follow the temporal evolution of the mode. For low AP experiments $D_{0}$ ranged from 50 to $150 \mathrm{~nm}$ and for high AP precursor concentrations the $D_{0}$ range was from 75 to $250 \mathrm{~nm}$.

We present results from the hygroscopicity measurements mainly as hygroscopicity parameter $\kappa$ (see also Eq. (1), Petters and Kreidenweis 2007) to account for the size dependence of the GF (Kelvin effect). $\kappa$ was calculated assuming the surface tension of pure water. A $\kappa$ of 0 corresponds to $\mathrm{GF}=1$. The use of $\kappa$ allows for direct comparison of hygroscopic growth factor measurements made at different dry diameters. It is also a convenient quantity to explore the water activity dependence of particle hygroscopicity by comparison of studies presenting $\kappa$ values from H-TDMA or CCNC measurements made at different water activities.

The V-TDMA was characterized with laboratory generated particles of known chemical composition to allow for a comparison of the results with other systems. The instrument residence time, diameter, and concentration of aerosols are important factors for heater characterization. Figure 3 shows the VFR for different compounds and particle diameters as function of the heater temperature.

Figure 3a displays the VFR of $\mathrm{NaCl}$, which is known to be non-volatile up to temperatures clearly above $200^{\circ} \mathrm{C}$ 
(Scheibel and Porstendoerfer, 1983), and thus the VFR measured by the V-TDMA is expected to be unity across the whole temperature range. The very small observed decrease in VFR to $\sim 0.97$ at $200^{\circ} \mathrm{C}$ might be either a restructuring effect, which would result in a more compact structure and therefore smaller effective volume, or evaporation of impurities from the nebulizing process of $\mathrm{NaCl}$. A similarly stable volatility behavior is observed in other studies (e.g. Modini et al. 2010). The plot of $\mathrm{NaCl}$ shows also the high precision of the instrument with less than $\pm 2 \%$ for VFR in a wide temperature range. Thermophoretical losses at $200{ }^{\circ} \mathrm{C}$ were determined to be $10-15 \%$ in particle number for $\mathrm{NaCl}$ particles with $D_{0}=35-200 \mathrm{~nm}$. This is in the range of other thermodenuders (Huffman et al., 2008; Park et al., 2008). We consider the losses as less relevant because the instrument is not quantitative in particle mass or number but rather measures the physical properties volatility and hygroscopicity.

Citric acid (Fig. 3b) was chosen as a reference substance because it is of rather high volatility similar to SOA; VFR starts to decrease at $T>70^{\circ} \mathrm{C}$. At temperatures above $110^{\circ} \mathrm{C}$ particles with $D_{0} \leq 300 \mathrm{~nm}$ are completely evaporated in our instrument. A small size-dependence due to kinetic reasons is seen: smaller particles tend to evaporate faster than larger particles (see e.g. Riipinen et al. 2010).

Ammonium sulfate particles (AS) (Fig. 3c) are often used for heater characterization; in our system AS particles start to volatilize at temperatures $T>\sim 100^{\circ} \mathrm{C}$. All AS particles volatilize completely (i.e. $\mathrm{VFR}<0.15$ ) at temperatures above $150^{\circ} \mathrm{C}$. In addition we show in panel c some AS thermograms from studies that we will use later for comparison of SOA thermograms (see Sect. 3.1). Some studies need a somewhat higher temperature to volatilize AS, but show a very similar slope (Jonsson et al., 2007; Meyer et al., 2009). The study from An et al. (2007) shows very different, earlier volatilization of AS compared to our system, where VFR of AS decreases at temperatures around $75^{\circ} \mathrm{C}$ and $150^{\circ} \mathrm{C}$ is needed to volatilize the particles with $D_{0}=100$ and $200 \mathrm{~nm}$ completely. There are also studies where AS starts to volatilize around $110^{\circ} \mathrm{C}$, but does not evaporate completely even at temperatures above $230^{\circ} \mathrm{C}$ (Huffman et al., 2008). However, the AS curves in this paper show a high variability and are therefore not included in Fig. 3c. The mass fraction remaining from AMS measurements for polydisperse AS in Wu et al. (2009) looks similar to our VFR thermogram of AS. It is characterized by a rapid decrease of the mass fraction remaining between $120^{\circ} \mathrm{C}$ and $160^{\circ} \mathrm{C}$. Villani et al. (2007) present an overview table with $160-180^{\circ} \mathrm{C}$ at $D_{0}=15-150 \mathrm{~nm}$ as lowest volatilization temperature for AS in their V-TDMA instrument while other studies report even higher temperatures.

Overall our instrument seems to be in a good temperature and residence time range for volatilization measurements of AS. Nevertheless, organic substances (e.g. citric acid) with relatively high volatility might be better suited to characterize a thermodenuder system than salts like AS because they often evaporate already at lower temperatures, i.e., more gentle heating is needed.

The calibration measurements presented in Fig. 3 show also the high precision of the V/H-TDMA instrument. The variance of precision at a constant temperature (same substance and $D_{0}$ ) is about 0.005 in VFR, which means clearly below $1 \%$. This demonstrates the high reproducibility of the VFR data and the same is true for the GF and $\kappa$ measurements (not shown here). The important factor is the precise sizing of the particles, which can be done very well with DMA systems. The absolute accuracy of the volatility and hygroscopicity data is influenced by further parameters e.g. temperature and $\mathrm{RH}$ measurements leading to higher absolute uncertainties. The absolute quantification is less important in this study than the temporal changes. Therefore we report the results with errors showing the reproducibility of the observations during the temporal evolution in the chamber.

\subsection{Smog chamber operation}

In all experiments, the clean smog chamber was humidified to $\sim 50 \% \mathrm{RH}$ at a temperature of $21 \pm 1{ }^{\circ} \mathrm{C}$ and these conditions stayed stable during the course of experiments. In a first step $\mathrm{O}_{3}$ was added to the chamber. After about $20 \mathrm{~min}$ when the $\mathrm{O}_{3}$ was distributed homogeneously in the bag the precursor AP was injected. We conducted experiments at two precursor concentrations of $40 \mathrm{ppb}$ ("high") and $10 \mathrm{ppb}$ ("low") $\alpha$-pinene mixing ratio, resulting in atmospherically relevant organic aerosol mass concentrations. The reaction resulted in immediate particle formation (first-generation SOA) from the reaction products of ozonolysis of the $\mathrm{C}=\mathrm{C}$ double bond in AP. As no OH scavenger was used about $30 \%$ of AP will react with $\mathrm{OH}$ radicals based on model calculations. Ozonolysis lasted a few hours until at least $90 \% \pm 5 \%$ of the AP precursor had reacted before the $\mathrm{OH}$ aging period was started (Fig. 1).

In a next step, $20 \mathrm{ppb}$ of 3-pentanol was added. Pentanol reacts with $\mathrm{OH}$ only, and thus its decay can be used as an $\mathrm{OH}$ tracer, in the same way as specific intermediate products. SOA was exposed to $\mathrm{OH}$ aging by either photolysis of HONO or ozonolysis of tetramethylethylene (TME) with the IUPAC name: 2,3-dimethyl-2-butene (Epstein and Donahue, 2008). The former are named "HONO photolysis experiments" throughout this study and the latter are called "dark $\mathrm{OH}$ (TME) experiments". A list with details of all conducted experiments is given in Table 2 .

TME ozonolysis is the $\mathrm{OH}$ source in dark $\mathrm{OH}$ (TME) experiments, however in some of these experiments we turned the lights on in the smog chamber to increase the $\mathrm{OH}$ source from photolysis of ozone during a part of the experiment. We introduced also additional experimental conditions with turning lights on and off during some experiments; one TME experiment was partly performed with UV lights on. All 
experiments with these special light conditions are commented in Table 2.

A HONO level of 15-20 ppb (as measured by a Long Path Absorption Photometer (LOPAP)) in the chamber was reached by passing pure air $\left(2 \mathrm{~L} \mathrm{~min}^{-1}\right)$ through a custom built vessel with sulfuric acid $\left(0.01 \mathrm{M} \mathrm{H}_{2} \mathrm{SO}_{4}\right)$ and sodium nitrite $\left(3 \times 10^{-3} \mathrm{M} \mathrm{NaNO}_{2}\right)$. The vessel and the setup of the HONO system we used are described elsewhere (Taira and Kanda, 1990). The flow from the HONO generator was passed through a filter to ensure that only the gas phase HONO without particles entered into the chamber. The addition of HONO started about one hour before the lights were turned on. In some high- $\mathrm{NO}_{\mathrm{x}}$ photo-chemical experiments (Table 2, exp. No. 6-8) 50-80 ppb NO was added in addition to the HONO. TME was continuously injected from a gas cylinder (Messer, TME $1000 \mathrm{~mol} \mathrm{ppm}$ in $\mathrm{N}_{2}$ 5.0) at a flow of $10 \mathrm{~mL} \mathrm{~min}^{-1}$ to maintain a TME mixing ratio between $0.5-1.5 \mathrm{ppb}$. The ozone level was usually higher in the TME experiments compared to HONO photolysis experiments because $\mathrm{O}_{3}$ was also needed for the ozonolysis of TME.

Different time axes as shown in the concept figure (Fig. 1) are used in the following. The progress of the experiment is described by either "time after AP injection" (relating to the start of the ozonolysis reaction) or "time after $\mathrm{OH}$ started" (relating to the start of the $\mathrm{OH}$ aging by lights on or start of TME injection) in units of hours (h). In addition two "chemical clocks" are used to represent the experiments with respect to their exposure to $\mathrm{O}_{3}$ or $\mathrm{OH}$, respectively. The $\mathrm{O}_{3}$ exposure (in ppbh) serves as chemical clock during the ozonolysis, and the $\mathrm{OH}$ exposure (in $\mathrm{cm}^{-3} \mathrm{~h}$ ) is used during the reaction period with $\mathrm{OH}$. The $\mathrm{OH}$ concentration was calculated from the decay rate of pinonaldehyde as measured by PTR-MS (see Barmet et al. (2011)). Pinonaldehyde is a reaction product of AP ozonolysis and proved to be a better tracer than pentanol (Barmet et al., 2011). OH concentrations in the experiments were between $2 \times 10^{6}$ and $10^{7} \mathrm{~cm}^{-3}$ (see Table 2). Due to the fast reaction of pinonaldehyde with $\mathrm{OH}$ the $\mathrm{OH}$ exposure was limited to about $15 \times 10^{6} \mathrm{~cm}^{-3} \mathrm{~h}$.

\section{Results and discussion}

First we present thermograms (temperature ramping in the V-TDMA heater) of some SOA experiments for comparison with reference substances (Sect. 2.2) and with other studies (Sect. 3.1). However, the main focus in this paper is on the temporal evolution of $\kappa(\mathrm{GF})$ and VFR during the ozonolysis (Sect. 3.2) and the $\mathrm{OH}$ exposure periods (Sect. 3.3). Thus time series at constant heater temperature $\left(T=70^{\circ} \mathrm{C}\right)$ in the V-TDMA and relative humidity $(\mathrm{RH}=95 \%)$ in the H-TDMA allow for a closer look at the ongoing processes during different reaction periods (see Sect. 2.3). Finally, the correlation of VFR and $\kappa$ (Sect. 3.4) will be investigated as well as the effect of additional light and the size dependence (Sect. 3.5) of these measured properties.

\subsection{Thermogram of SOA and comparison with other studies}

Thermograms with well known substances characterize the V-TDMA (Fig. 3) as discussed above. Such thermal information can also be used to gain information on the complex chemical nature of SOA. Figure 4 shows mean VFR values versus heater temperature for all three types of AP SOA experiments (circles). Four thermograms from other studies of AP SOA (squares) are compared to our measurements. The error bars represent the standard deviations of VFR (vertical) and the temperature (horizontal). Large vertical error bars are due to real volatility changes of the chamber aerosol during the course of the experiment and do not reflect the V-TDMA accuracy. All our thermograms are similar within these uncertainties and show no distinct $D_{0}$ or experiment type dependence.

A significant decrease of VFR starts at $\sim 50{ }^{\circ} \mathrm{C}$ and at $90{ }^{\circ} \mathrm{C} 50 \%$ of the particle volume is volatilized. Temperatures around $150{ }^{\circ} \mathrm{C}$ are required to reduce the VFR to $10 \%$. This is a much wider temperature range than for pure citric acid or ammonium sulfate and is explained with different compounds in the chamber SOA possessing volatilities ranging from rather semi-volatile to low-volatile. Although the three experiment types (ozonolysis, HONO photolysis and dark OH (TME) experiments) cannot be compared directly as the data were acquired at different stages of the experiments, we fitted our thermograms with an error function. The fitted error function (erf) (Fig. 4, black line), is only valid above $50^{\circ} \mathrm{C}$. It is set to 1 as maximum and has the following equation with $T$ as the heater temperature:

$\mathrm{VFR}=0.91-0.911 \times \operatorname{erf}\left(\frac{T\left[{ }^{\circ} \mathrm{C}\right]-53.15}{82.5}\right)$

This empirical function was simply chosen as it represents the observations in the most suitable way. It is helpful to extrapolate the volatility data from other experiments during this study when the temperature was set to $70^{\circ} \mathrm{C}$ continuously to compare e.g. with other studies. Comparison of our measurements with other AP SOA studies (squares in Fig. 4) shows the best agreement with the instrument and measurements from Meyer et al. (2009), from Cappa and Wilson (2011) and Jonsson et al. (2007) for low temperatures and Huffman et al. (2009) for higher temperatures. These and our SOA thermograms lie between the two other studies from An et al. (2007) and Paulsen et al. (2005). Different residence times (RT) in the heated zone are an important cause among other instrumental differences for the disparate thermograms. The plug flow RT of all these studies are $<1 \mathrm{~s}$ (Baltensperger et al., 2005; Paulsen et al., 2005), 2.8 s (Jonsson et al., 2007), $\sim 3 \mathrm{~s}$ (Meyer et al., 2009), 15 s (Cappa and Wilson, 2011), 21.2 s (Huffman et al., 2008, 2009), $23 \mathrm{~s}$ (this study) and $31.6 \mathrm{~s}$ (An et al., 2007), respectively. If the above papers stated the centerline RT at laminar flow we converted it to plug flow RT (factor 2). Our instrument seems 


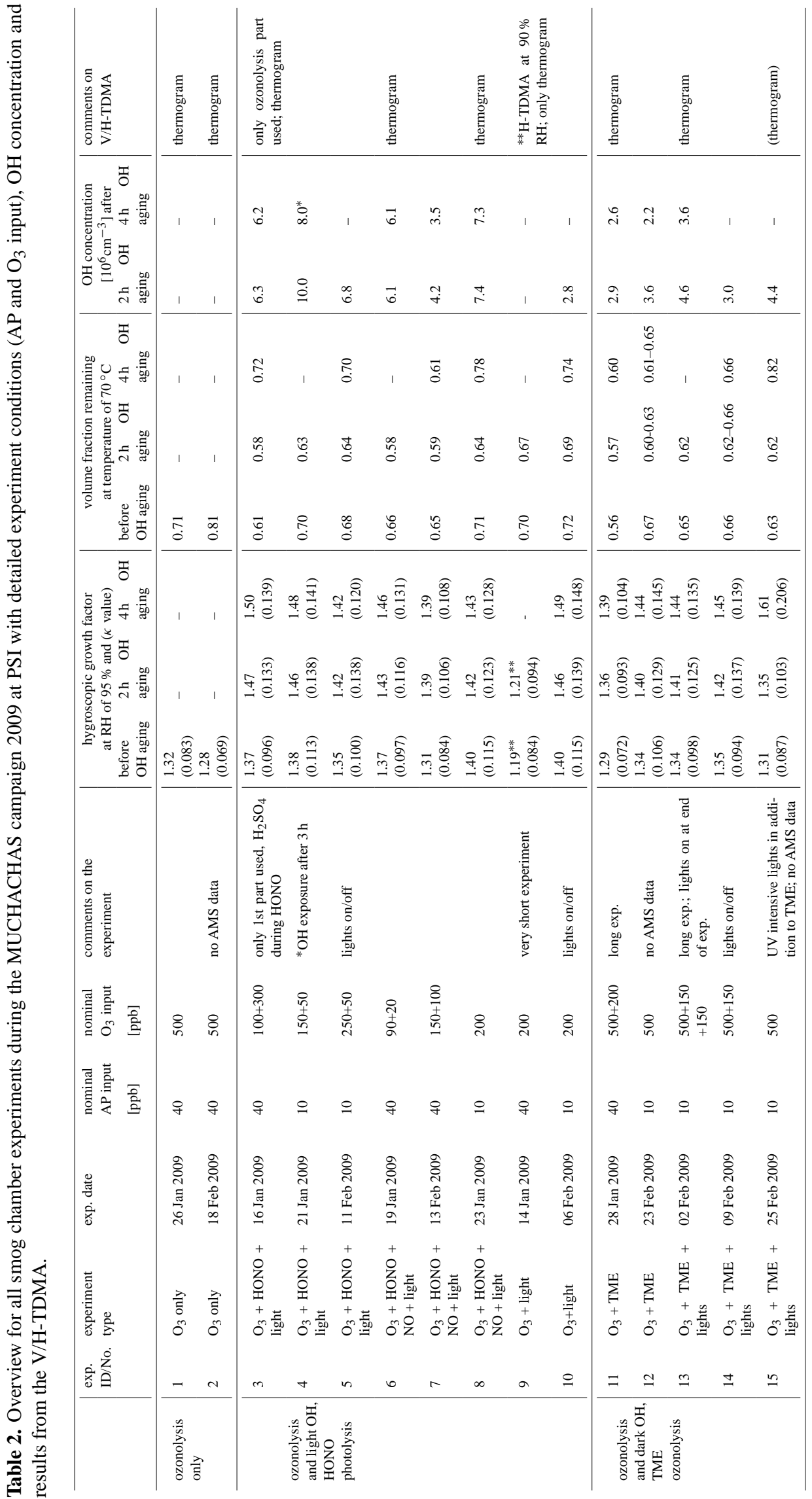




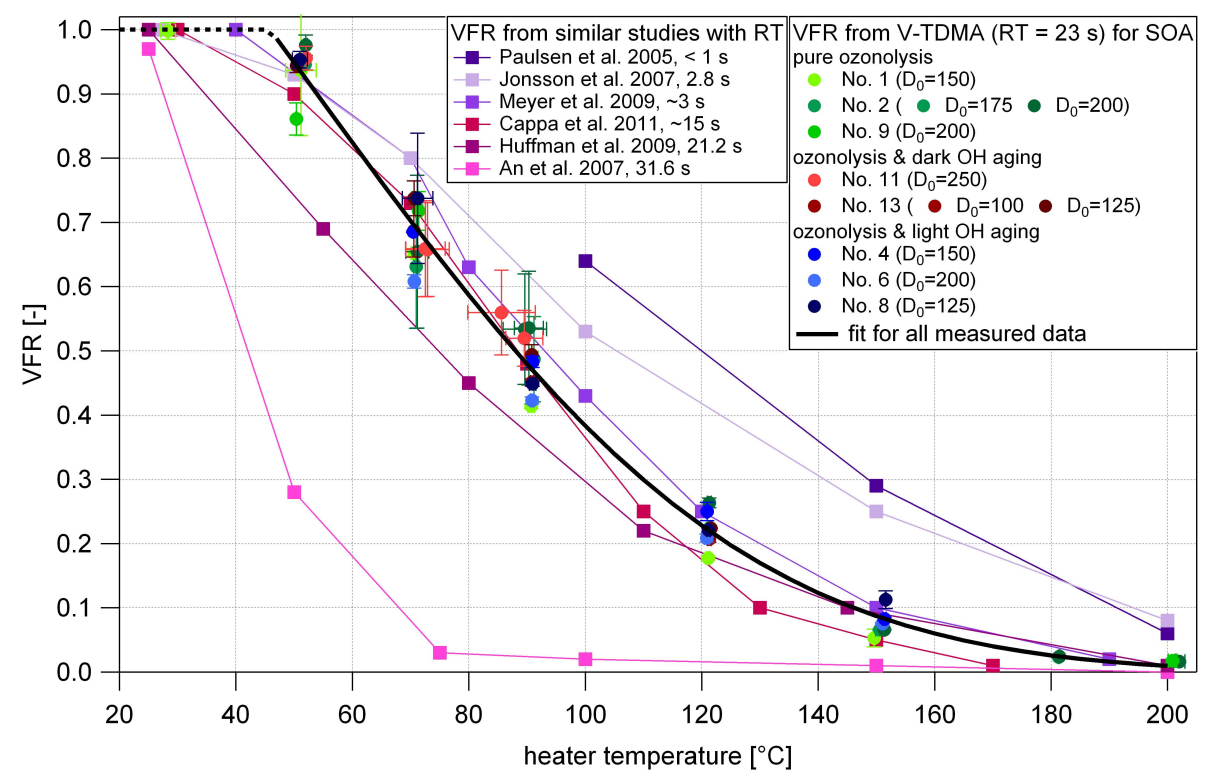

Fig. 4. Mean VFR measured for SOA from three different experiment types, distinguished with greenish, reddish and bluish color, at various heater temperatures with error bars representing the standard deviation of VFR and temperature of multiple measurements during the experiment (circles). Literature data (squares) from similar SOA studies were added for comparison. The black solid line represents a fit through all measured data of this study.

to have the second longest RT, at ambient temperature (see Sect. 2.2); only the RT from An et al. (2007) is longer. This could explain the stronger volatilization of SOA at relatively low temperatures in their study at least partly (as also seen in Fig. 3c). On the other hand shorter RT leads to higher VFR (Baltensperger et al., 2005; Paulsen et al., 2005; Jonsson et al., 2007). With our long RT we are able to use low temperatures in the heater and minimize kinetic limitations of evaporation and hope to be close to equilibrium, even though this is probably not the case as suggested recently (Riipinen et al., 2010).

The VFR of this comparison is generally following the RT, i.e. a shorter RT leads to higher VFR and vice versa. This is expected if the evaporation is kinetically limited and no equilibrium is reached in neither of these instruments (Riipinen et al., 2010). Further reasons for small differences in the SOA thermograms may be the type of AP SOA, its concentration, and experimental conditions. Recent studies by Vaden et al. (2011) as well as Cappa and Wilson (2011) postulate a glasslike modification of the AP SOA which would even inhibit effective evaporation within a reasonable RT. Other instrumental reasons e.g. initial particle size, monodisperse or polydisperse measurement, use of a charcoal denuder after the heating section or different experimental conditions may also lead to these variations. The latter is already reflected in the scatter of our data taken from different experiments like ozonolysis and/or $\mathrm{OH}$ exposure. Altogether, there are many indications that evaporation studies of SOA are quite challenging and need further attention.
Overall, the comparison of thermograms gives an orientation on our V-TDMA characteristics and shows the importance of the residence time, instrument specific properties and experimental conditions. The decrease in VFR with temperature is experienced over a relatively large temperature range and offers a sensitive range from $\sim 60$ to $100^{\circ} \mathrm{C}$ to study the SOA volatile properties. A constant oven temperature of $70^{\circ} \mathrm{C}$ was chosen to track temporal changes in the SOA volatility during the chamber reactions discussed in the following.

\subsection{Ozonolysis $-\mathrm{O}_{3}$ induced condensation and ripening}

The first step in each experiment was the ozonolysis of AP to form SOA mass (Fig. 1). The initial $\mathrm{O}_{3}$ concentration varied with the type of experiment. Figure 5a shows the time trends of the fraction of AP reacted, the organic aerosol mass, the volatility as VFR, and the hygroscopicity both as $\kappa$ value and as GF at $95 \% \mathrm{RH}$. The markers are colored according to the initial $\mathrm{O}_{3}$ concentration; filled symbols represent low AP and open symbols represent high AP input.

High $\mathrm{O}_{3}$ concentrations led to a fast reaction of AP and a rapid formation of SOA (Fig. 5, panel $\mathrm{a}_{1}-\mathrm{a}_{2}$ ). It took roughly one hour to reach the "90\% AP reacted" level (see vertical lines in Fig. 5a). At lower $\mathrm{O}_{3}$ concentrations this took 2-3 times longer and the final SOA mass was lower. This may have two reasons. Firstly, more semi-volatile compounds are lost to the walls and do not condense on the particles. Secondly, organic radical-radical reactions 

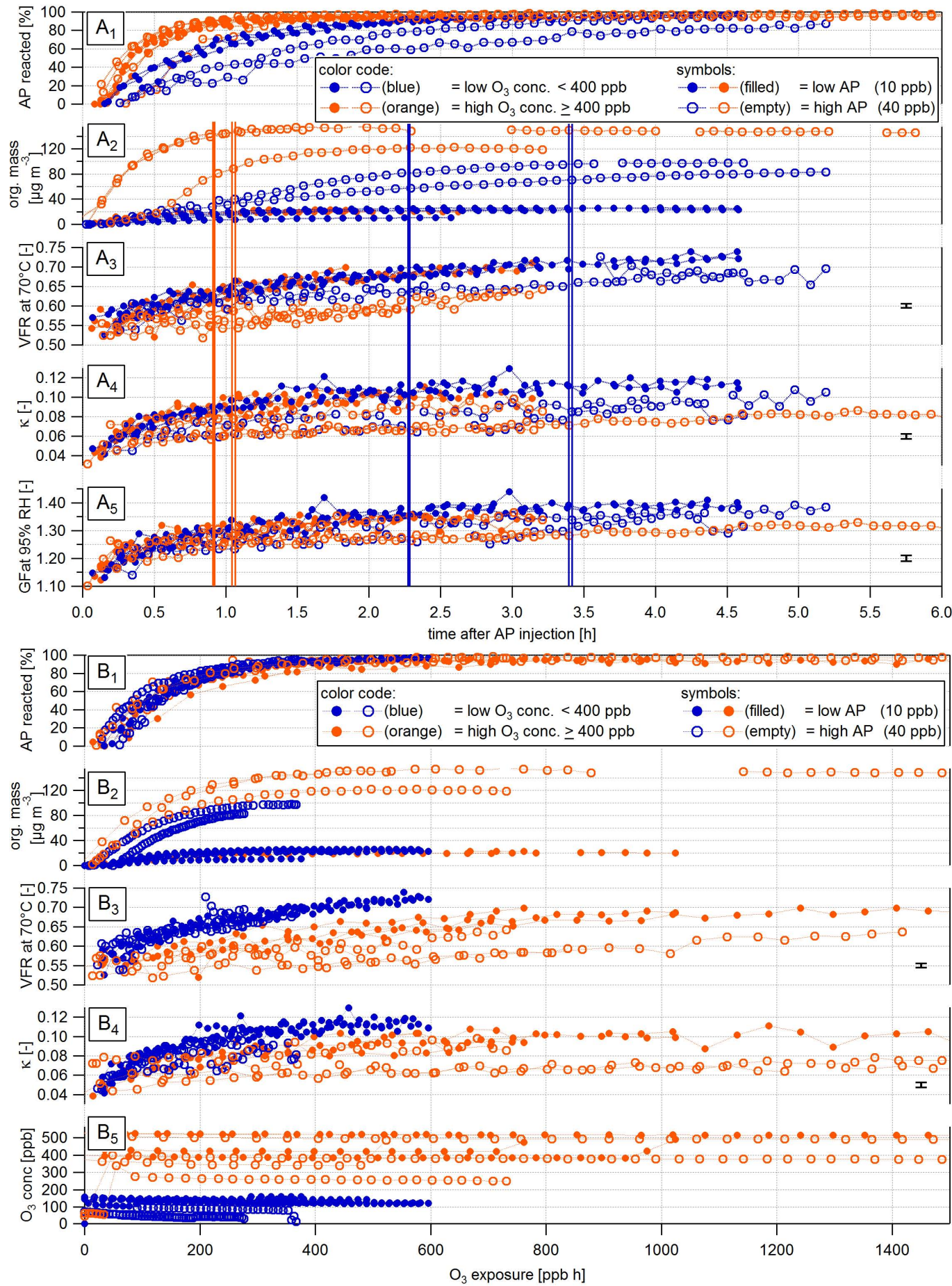

Fig. 5. All experiments of the ozonolysis part only. The relative fraction of AP reacted, wall-loss corrected SOA mass concentration (org. mass), volatility expressed as VFR at $70^{\circ} \mathrm{C}$ and the hygroscopic parameter $\kappa$ are presented on different time axes, in panel (a) as "time after AP injection" and in panel (b) as " $\mathrm{O}_{3}$ exposure", which is used as "chemical clock". The color indicates the $\mathrm{O}_{3}$ concentration for low $\mathrm{O}_{3}$ $(<400 \mathrm{ppb})$ and for high $\mathrm{O}_{3}(\geq 400 \mathrm{ppb})$. The filled symbols represent the low $\alpha$-pinene (AP) (10 ppb) and open symbols the high AP (40 ppb) precursor concentration experiments. The panels $\left(\mathbf{a}_{1}\right)-\left(\mathbf{a}_{4}\right)$ and $\left(\mathbf{b}_{1}\right)-\left(\mathbf{b}_{4}\right)$ present corresponding data, respectively. In addition panel $\left(\mathbf{a}_{5}\right)$ shows the GF at $95 \%$ RH and (b5) shows the $\mathrm{O}_{3}$ concentration. The vertical lines in panel (a) indicate roughly $( \pm 5 \%)$ the $90 \%-\mathrm{AP}$-reacted value for the four main experiment conditions: high/low AP (open/solid line, respectively), combined with high/low $\mathrm{O}_{3}$ (orange/blue color, respectively). Exemplary error bars for volatility and hygroscopicity data represent the reproducibility. Additional scatter of the data points is caused by the fact that different dry sizes are measured. 
are decreased, eventually leading to less semi-volatile compounds contributing to SOA.

The physical parameters $\kappa$ and VFR data (Fig. 5, panel $\mathrm{a}_{3}-\mathrm{a}_{4}$ ) split mainly into two groups comprising low and high concentration AP experiments. Experiments with high SOA mass have generally a higher volatility (lower VFR) and lower hygroscopicity. In case of the low AP experiments VFR increases steadily from 0.55 to 0.7 after $4.5 \mathrm{~h}$ of reaction. Even after most of the AP had reacted (90\%-level) VFR keeps increasing. The high AP experiments show a similar but less pronounced trend. During the condensation phase VFR slightly increases. The hygroscopicity of low and high AP experiments shows a similar evolution but separates slightly with time (Fig. 5a $\mathrm{a}_{4}, \mathrm{a}_{5}$ ). Duplissy et al. (2008) found a distinct mass concentration dependence of GF for an $\alpha$ pinene photooxidation experiment, i.e. a lower GF at a higher particle concentration. This was attributed to volatile and less oxygenated vapor condensing at higher mass concentrations lowering the GF. Here we do observe only a slightly lower GF for the high concentration experiments after the SOA has evolved, but Duplissy et al. (2008) had higher AP mixing ratios $(>120 \mathrm{ppb})$ in their study and investigated a different system (photochemistry instead of ozonolysis), which can explain the differences in the findings.

The hygroscopicity is presented in Fig. 5 panel $a_{4}-a_{5}$ in terms of $\kappa$ and GF. Both show the same features (small difference between high and low AP experiments) and differences between $\kappa$ and GF are mainly seen during the first 1$2 \mathrm{~h}$ of ozonolysis where the selected diameters are small and differ due to fast particle formation. In some experiments (open blue circles at about $5 \mathrm{~h}$, two diameters are measured alternately) the GF seems to smooth size effects of different diameters. The presented $\kappa$ values are a good proxy for the particle hygroscopicity because the diameter dependence of the Kelvin effect is taken into account (by assuming a surface tension of pure water). Thus we will present the hygroscopicity data as $\kappa$ values in the following. The $\kappa$ values start at about 0.04 in the beginning of all experiments and then increase during the condensation period. Thereafter, $\kappa$ remains almost constant. Similar as for VFR, the low AP concentration experiments group together and show a higher $\kappa$ than the high AP concentration experiments. However, the values remain within a rather narrow range of 0.08-0.12.

Figure $5 \mathrm{~b}$ (panel $\mathrm{b}_{1}-\mathrm{b}_{4}$ ) shows the same experiments and parameters as Fig. $5 \mathrm{a}_{1}-\mathrm{a}_{4}$ but as a function of the $\mathrm{O}_{3}$ exposure (in ppbh). The trends of $\kappa$ and VFR are split into low and high $\mathrm{O}_{3}$ concentration experiments. After about $350 \mathrm{ppbh} 90 \%$ of $\alpha$-pinene has reacted in all experiments and we would expect a similar composition of the products. However, we see at this exposure higher VFR and $\kappa$ values for the low $\mathrm{O}_{3}$ concentration experiments. The reason for this could be twofold. First, radical-radical reactions are decreased leading to a somewhat different product distribution (SOA mass is also decreased, see above). Second, at low $\mathrm{O}_{3}$ concentrations it takes longer until $90 \%$ AP has reacted and the SOA had thus more time to evolve. It is clearly seen that after $350 \mathrm{ppb}$ h the VFR keeps on increasing steadily although not much additional SOA mass is formed. On the other hand $\kappa$ remains nearly constant. The increase of VFR could indicate an oligomerization process while this would imply a decrease of $\kappa$. Shilling et al. (2007) observed that $\mathrm{O}_{3}$ can heterogeneously oxidize aldehydes to acids which would decrease VFR and increase $\kappa$ (as dissociation of acids increases the van't Hoff factor). A control experiment with an excess of AP during the ozonolysis shows in the AMS the same chemical changes as with an excess of $\mathrm{O}_{3}$. This does not support heterogeneous oxidation as the cause of this steady increase of VFR. At present we do not have an explanation for this evolution of the SOA. We call this unspecified process or processes ripening of the SOA.

\subsection{SOA aging - $\mathrm{OH}$ induced chemical aging}

During the first period of the experiment the precursor was removed by ozonolysis, forming mainly first generation and a fraction of second generation gaseous oxidation products, as well as a certain mass of SOA. We then turned on an $\mathrm{OH}-$ radical source and monitored any changes in the amount and properties of SOA. Figure 6 shows the organic aerosol mass (panel a), the VFR at $70^{\circ} \mathrm{C}$ (panel b), as well as $\kappa$ and O:C ratio (panel c) for a low (green) and a high (blue) AP concentration using $\mathrm{HONO}$ photolysis as $\mathrm{OH}$ radical source. The time axis is given as "time after lights on" (TALO), which means that negative values denote the previous ozonolysis period. Immediately after the onset of the $\mathrm{OH}$ radical source additional SOA mass is formed. Figure 6a shows that after correction for wall loss the SOA mass increases by $40-100 \%$. This is a lower limit as the wall loss correction presented here is conservative - the effects of aging on SOA levels will be discussed in detail in a separate publication. We divide the $\mathrm{OH}$ induced chemical aging period into a period with substantial mass gain (TALO $\sim 0$ to $2 \mathrm{~h}$ ), and a period without significant mass gain (TALO $\sim 2$ to $4.5 \mathrm{~h}$ ).

The hygroscopicity parameter $\kappa$ (Fig. 6c) increases significantly by more than $30 \%$ during the $\mathrm{OH}$ induced chemical aging period with substantial mass gain. The increase in $\kappa$ suggests that the SOA mass gain during aging is driven by molecules with a lower molecular weight than the fresh SOA. This indicates the condensation of smaller molecules than the average of previous condensed phase species. The trend of $\kappa$ levels then off and stays constant during the $\mathrm{OH}$ induced chemical aging period. The $\mathrm{O}: \mathrm{C}$ ratio is constant or slightly decreasing during the ozonolysis, while it correlates well with $\kappa$ during the $\mathrm{OH}$ induced chemical aging period. Thus $\mathrm{OH}$ exposure leads to condensation of higher oxidized species onto the existing SOA. During the period without significant mass gain the $\mathrm{O}: \mathrm{C}$ ratio remains constant.

Contrary to this the VFR (Fig. 6b) abruptly decreases after $\mathrm{OH}$ aging commences (turning lights on) and starts to stabilize after about one hour of aging with $\mathrm{OH}$ radicals. 


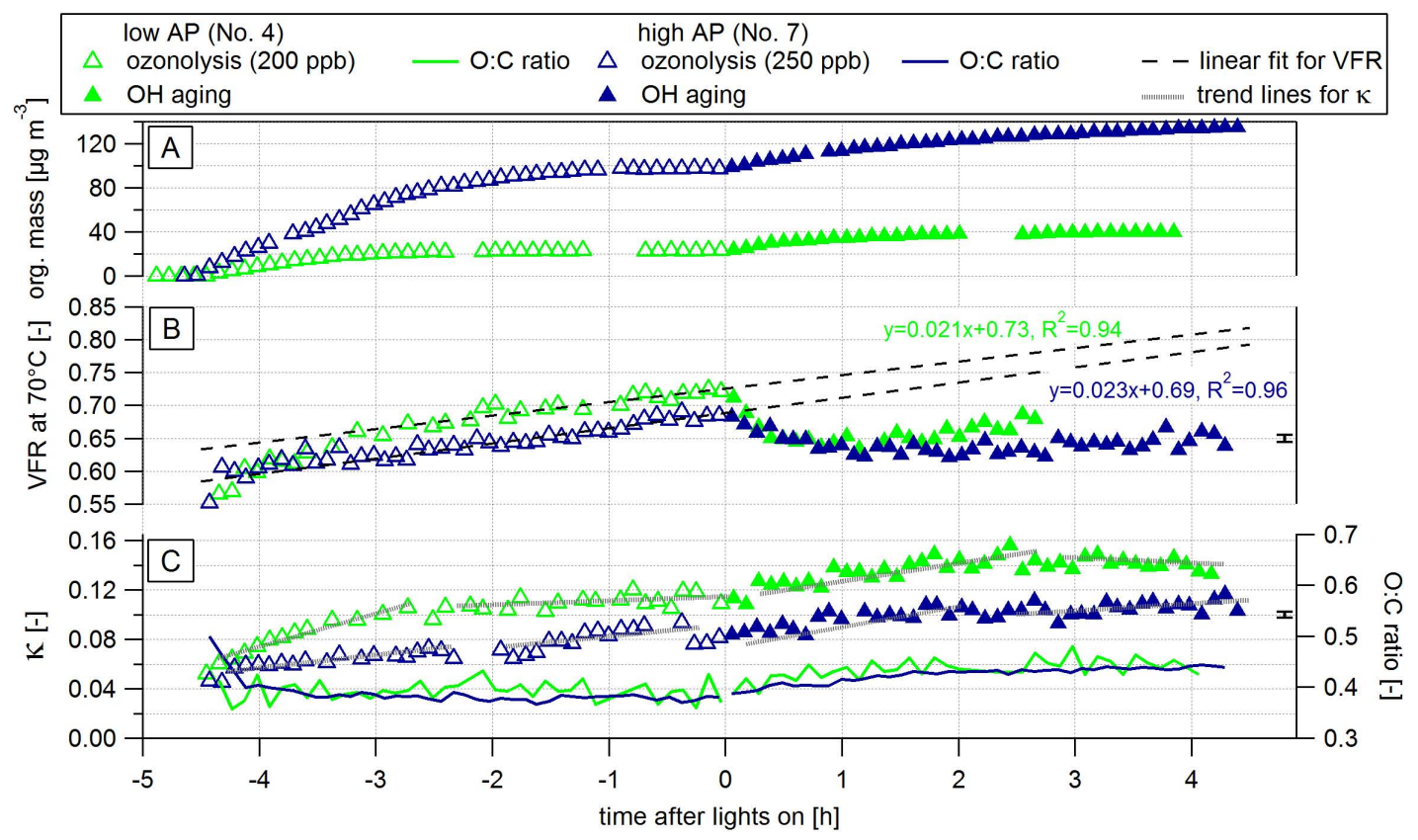

Fig. 6. Time series of two $\alpha$-pinene (AP) ozonolysis experiments followed by reaction with OH from HONO photolysis. The two periods of the experiment, ozonolysis and reaction with $\mathrm{OH}$, are distinguished by open and closed symbols, respectively, and green and blue color is used for the low (10 ppb) and high (40 ppb) AP precursor concentration experiment, respectively. Panel (a) shows the organic aerosol mass (wall-loss corrected), panel (b) the VFR at $70^{\circ} \mathrm{C}$ and in panel (c) the hygroscopicity parameter $\kappa$ (left axis) as well as the O:C ratio (right axis). The evolution of the VFR during ripening (ca. from -3 to $0 \mathrm{~h}$ ) was linearly fitted and extrapolated to indicate the trend expected without reaction with $\mathrm{OH}$. The grey dotted lines shown in panel (c) help to guide the eye to see the changing trends of $\kappa$ in the four periods of the experiment. Exemplary error bars in panel (b) and (c) represent the reproducibility for volatility and hygroscopicity data, respectively. Additional scatter of the data points is caused by the fact that different dry sizes are measured.

In the last period of the experiment, during the $\mathrm{OH}$ induced chemical aging without significant mass gain, the VFR tends to increase slightly. The newly added SOA mass after the onset of $\mathrm{OH}$ oxidation seems to have a higher volatility (lower VFR) than the previously existing SOA from the ozonolysis. The volatility of the newly added SOA was estimated by assuming simple volume mixing, i.e.

$\mathrm{VFR}_{\text {mixed }}=\epsilon_{\text {old }} \times \mathrm{VFR}_{\text {old }}+\epsilon_{\text {new }} \times \mathrm{VFR}_{\text {new }}$

where the indices "old", "new" and "mixed" stand for the SOA from the ozonolysis, the SOA added by $\mathrm{OH}$-aging, and the mixed SOA particle, respectively, and $\epsilon$ denotes the volume fractions of the SOA components in the mixed particle. Solving Eq. (5) for $\mathrm{VFR}_{\text {new }}$ provides:

$\mathrm{VFR}_{\text {new }}=\frac{\mathrm{VFR}_{\text {mixed }}-\epsilon_{\text {old }} \times \mathrm{VFR}_{\text {old }}}{1-\epsilon_{\text {old }}}$

$\mathrm{VFR}_{\text {mixed }}$ is directly measured by the V-TDMA. $\epsilon_{\text {old }}$ is derived from the organic aerosol mass measurements by the AMS before and after new material was added, thereby assuming the same density for the old and new mass. VFR is obtained by extrapolating a linear fit through the last $3 \mathrm{~h}$ of ozonolysis data, as indicated by the dashed lines in Fig. 6b. In doing so we assume that the $\mathrm{OH}$ exposure does not cause additional oxidation of the old SOA within this short time span as heterogeneous $\mathrm{OH}$ uptake is much slower compared to SOA formation by $\mathrm{OH}$ oxidation of gaseous precursors. Fortunately, the calculations are anyway not very sensitive to the exact value assumed for $\mathrm{VFR}_{\text {old }}$.

Based on Eq. (6) the VFR of the newly condensed material after one hour of exposure to $\mathrm{OH}, \mathrm{VFR}_{\text {new }}$, is calculated to be 0.47 and 0.21 for the low and high precursor experiment respectively. The calculated $\mathrm{VFR}_{\text {new }}$ for all experiments is in a similar range from 0.09 to 0.49 (at $70^{\circ} \mathrm{C}$ ) indicating highly volatile material. These numbers are to be taken with a grain of salt given that the simple volume mixing rule ignores e.g. the influence of absorptive partitioning and kinetic effects on $\mathrm{VFR}_{\text {mixed }}$. Nevertheless, they confirm that the SOA mass added by $\mathrm{OH}$ aging is distinctly more volatile than the SOA mass resulting from the ozonolysis. A pathway of formation could be functionalization of volatile oxidation products reducing their volatility by one to two orders of magnitude such that they can now partition into the aerosol. This also increases the $\mathrm{O}: \mathrm{C}$ ratio relative to the preexisting SOA. However, since the increase of $\kappa$ indicates the condensation of smaller compounds we conclude that most of the newly condensed volatile fraction occurs from fragmentation reactions. The breaking of the skeleton leads 


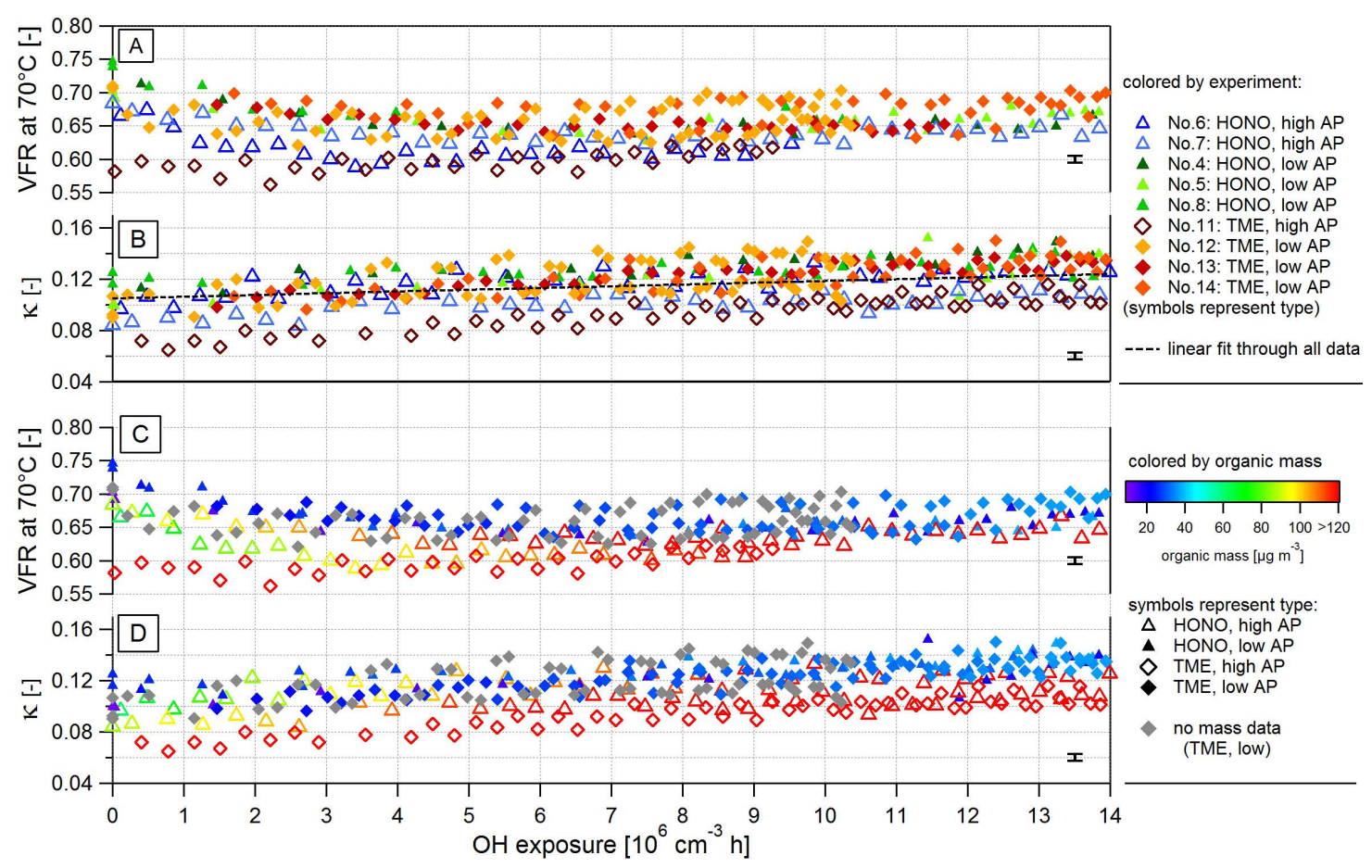

Fig. 7. Volatility, expressed as VFR at $70^{\circ} \mathrm{C}$, and hygroscopicity parameter $\kappa$ plotted against the "chemical clock" OH exposure shown for the reaction with $\mathrm{OH}$ part of the experiments only. The color code in panel (a) and (b) represents the individual experiments; while the symbols shape and filling indicate the experiment type and $\alpha$-pinene (AP) input concentration, respectively. The filled symbols represent the low AP (10 ppb) and open symbols the high AP (40 ppb) precursor concentration experiments. Panel (c) and (d) show exactly the same data as panels (a) and (b), now arranged in groups of experiment type and color coded by their wall-loss corrected organic aerosol mass (note that the red color ranges from 120 to max. $255 \mu \mathrm{g} \mathrm{m}{ }^{-3}$ ). Exemplary error bars at the right end of each panel represent the precision of the measurements.

to radicals which react with molecular oxygen to form finally stable products. In this way small highly oxidized molecules of low volatility may be formed. This would be in agreement with a decrease of VFR and an increase in $\kappa$ and O:C ratio.

In Fig. 7 all experiments are summarized. Panels a and $\mathrm{b}$ group the experiments according to the type of $\mathrm{OH}$ radical source (HONO photolysis and dark OH (TME)) while panels $\mathrm{c}$ and $\mathrm{d}$ show the dependence of $\kappa$ and VFR on the wall-loss corrected SOA mass. OH exposure is used as a chemical clock to bring all experiments on a comparable time scale. Some experiments are not shown in their full experimental length because this chemical $\mathrm{OH}$ clock is limited in time to when the pinonaldehyde concentration was still above the limit of detection of the PTR-MS.

Overall, the time trends of $\kappa$ and VFR (Fig. 7a, b) are similar for all experiments and to those two experiments discussed above and shown in Fig. 6. The initial values of $\kappa$ and VFR are somewhat variable, depending on the preparation of the SOA by ozonolysis. The $\kappa$ values start at $0.07-0.12$ and increase to $0.10-0.15$ during the $\mathrm{OH}$ induced chemical aging with substantial mass gain. During the second period (after about $8 \times 10^{6} \mathrm{~cm}^{-3} \mathrm{~h}$ ) $\kappa$ stays more or less constant. A linear regression over the whole $\mathrm{OH}$ induced chemical aging period results in a mean straight line of $\kappa=1.37 \times 10^{-9} x+$ $0.105\left(R^{2}=0.46\right)$, where $x$ is the $\mathrm{OH}$ exposure.

The VFR decreases during the $\mathrm{OH}$ induced chemical aging with substantial mass gain and increases during the aging period without significant mass gain after about $8 \times 10^{6} \mathrm{~cm}^{-3} \mathrm{~h}$ $\mathrm{OH}$ exposure. The high concentration dark $\mathrm{OH}$ (TME) experiment No. 11 is an exception - VFR increases during both periods as it is the experiment with the highest organic aerosol mass. Nevertheless the VFR of the newly condensing mass is still much lower than the $\mathrm{VFR}_{\text {old }}$ as calculated from Eq. (6). The type of $\mathrm{OH}$ source, dark $\mathrm{OH}$ (TME) and HONO photolysis does not show differences in the particles' hygroscopicity or volatility behavior. This also indicates that high or low $\mathrm{NO}_{\mathrm{x}}$ conditions during HONO photolysis experiments have no clear influence on $\kappa$ and VFR (see Table 2).

In panel $\mathrm{c}$ and d (Fig. 7) the $\kappa$ and VFR data of each experiment are colored by the SOA mass concentration measured by the AMS. The volatility of the high mass experiments is generally higher (lower VFR) than for the low AP experiments throughout the experiment. The spread of VFR becomes narrower with time. At the end of the $\mathrm{OH}$ induced chemical aging period $\kappa$ values are lower for high AP experiments compared to the low concentration ones. 

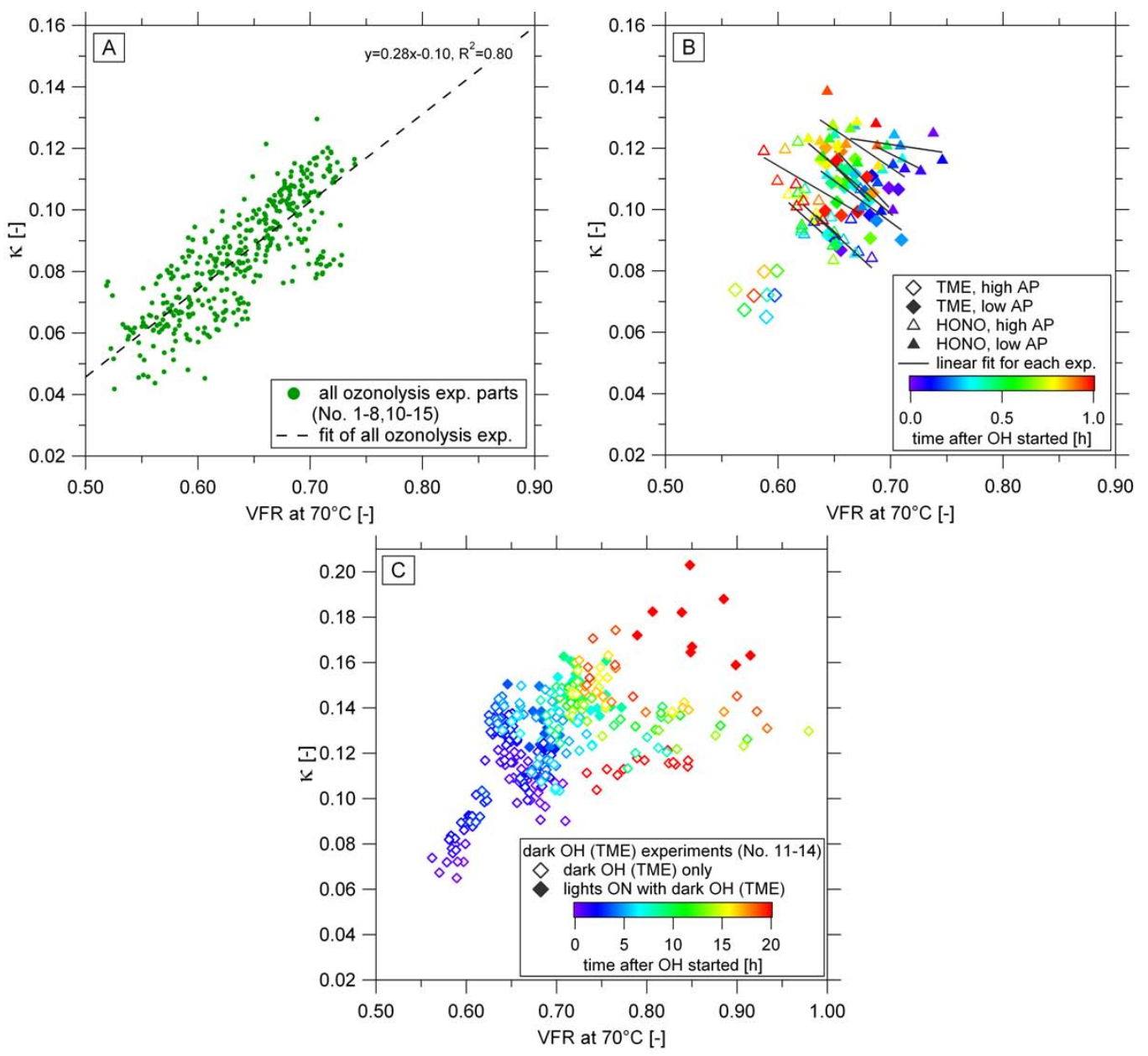

Fig. 8. Correlation of hygroscopicity parameter $\kappa$ and VFR at $70{ }^{\circ} \mathrm{C}$ of $\alpha$-pinene SOA for several experiments and sections of experiments. Panel (a) shows the correlation for all available experiments during the ozonolysis part only. The positive correlation of $\kappa$ and VFR can be presented by a linear fit. Panel (b) shows the anti-correlation of $\kappa$ and VFR during the first hour after OH aging was started for dark OH (TME) experiments (diamonds) and HONO photolysis experiments (triangles). The same correlation is presented in panel (c) for experiments No. 11-14 during the reaction with $\mathrm{OH}$ from TME in absence of light (open symbols), sometimes with addition of lights (closed symbols). The data shown in panel (b) and (c) are color coded by time after $\mathrm{OH}$ started.

\subsection{Correlation of $\kappa$ and VFR}

Here we present $\kappa$ and VFR in direct relationship to each other. We do it separately for the different periods as there can be a correlation or anti-correlation depending on the period. Figure 8a shows for all available ozonolysis experiments $\left(14\right.$ in total) a good $\left(R^{2}=0.80\right)$ correlation of $\kappa$ and VFR. The observed scatter is attributed to different experimental conditions and periods. The correlation is determined by the strong trends in $\kappa$ and VFR during the $\mathrm{O}_{3}$ induced condensation period.

The first hour of $\mathrm{OH}$ induced chemical aging is presented separately in Fig. 8b. In general an anti-correlation of $\kappa$ and VFR is observed for all experiments although the magnitude and duration of this opposite trends for $\kappa$ and VFR is varying.
In some dark $\mathrm{OH}$ (TME) experiments we turned the lights on (and off) in the smog chamber to have an additional $\mathrm{OH}$ source. The idea was to check the influence on the aging process and to study the possible effects on volatility and hygroscopicity due to that. The correlation of $\kappa$ and VFR in Fig. 8c allows a closer look at the temporal evolution during $\mathrm{OH}$ induced chemical aging and the effect of "lights on" in four dark OH (TME) experiments (No. 11-14, see Table 2). Generally, the dark $\mathrm{OH}$ exposure experiments show a positive correlation between $\kappa$ and VFR for about the first $10 \mathrm{~h}$. Afterwards only the VFR increases further. Only an enhanced oxidation rate by turning on the lights producing more $\mathrm{OH}$ radicals increases VFR and $\kappa$ even more (up to $\kappa=0.2$ ). It should be cautioned here that the opposing trends of VFR and $\kappa$ during the $\mathrm{OH}$ induced chemical aging with substantial mass gain period are buried in the scatter plot. 


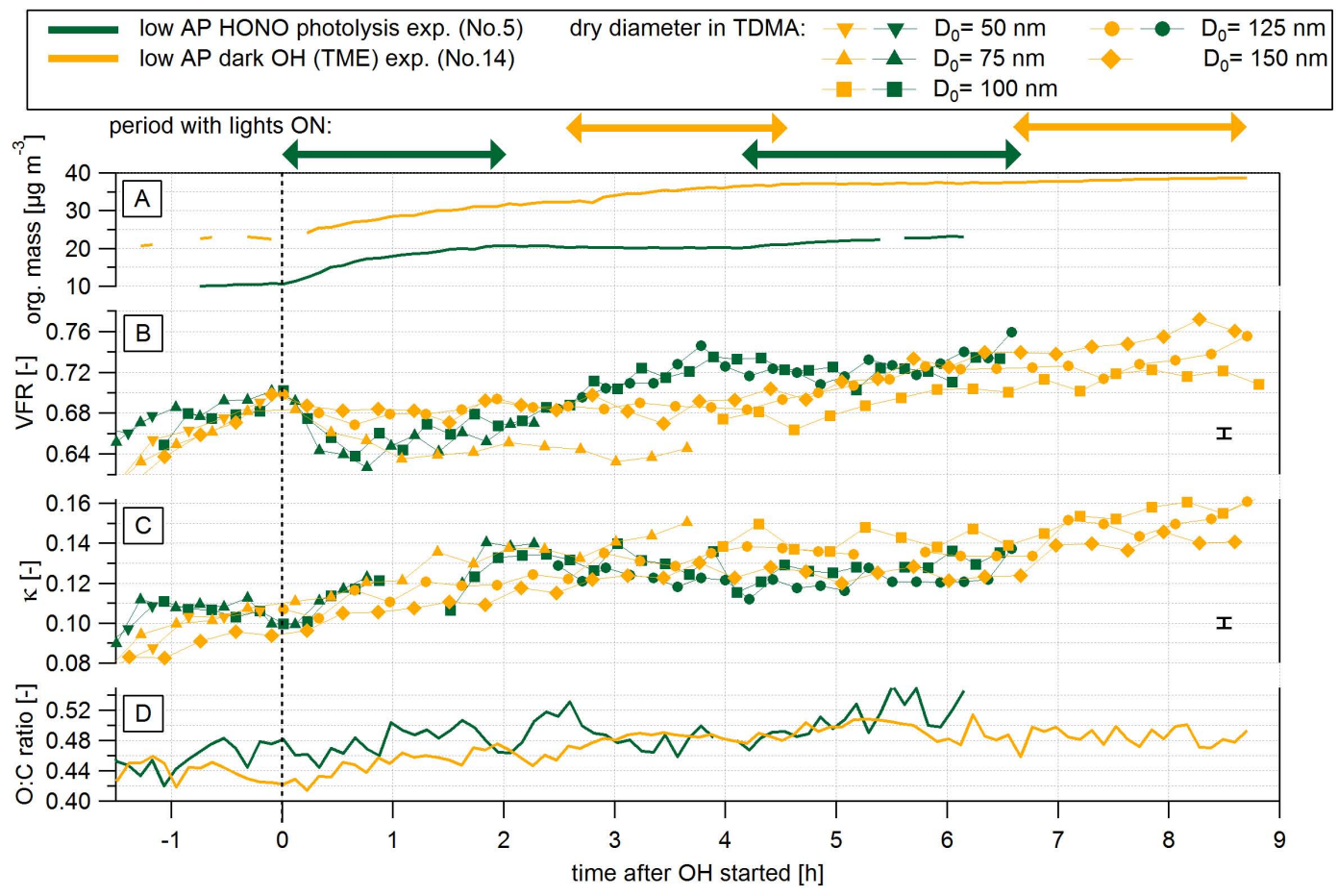

Fig. 9. Results from low concentration $\alpha$-pinene experiments No. 5 (OH from HONO photolysis, green) and 14 (OH from TME, yellow) are plotted as time series of: (a) wall-loss corrected organic aerosol mass (org. mass), (b) volatility as VFR at $70^{\circ} \mathrm{C}$, (c) hygroscopicity parameter $\kappa$, and (d) O:C ratio. The lights were intermittently turned on and off during these two experiments. The double arrows above the figure indicate the periods with lights on. The symbols and colors in panel (b) and (c) indicate the dry diameter $\left(D_{0}\right)$ for the TDMA measurement and show the size dependence of volatility and hygroscopicity. Exemplary error bars at the right end of each panel represent the reproducibility of the measurements.

\subsubsection{Maximum hygroscopicity and minimum volatility with addition of UV light}

In one experiment we removed the UV-filters from the xenon lamps in the chamber. The combination of $\mathrm{OH}$ production with TME and ozone photolysis with unfiltered UV light results in a higher hygroscopicity (experiment No. 15, not shown in Fig. $8 \mathrm{c})$. The highest hygroscopicity $(\kappa=\sim 0.21)$ and lowest volatility (highest VFR $=\sim 0.82$ at $70^{\circ} \mathrm{C}$ ) of all experiments were reached in this experiment after only $4 \mathrm{~h}$ of $\mathrm{OH}$ aging (see Table 2). The experiment with second highest $\kappa$ and VFR after several hours of aging $(\kappa=\sim 0.17$ and $\mathrm{VFR}=\sim 0.80$ ) was the one with dark $\mathrm{OH}$ and normal lights on (No. 13). However, this was a long experiment with high $\mathrm{O}_{3}$ concentration and we cannot decouple the effects. We conclude that both the additional OH (e.g. TME + lights) and enough time are important for aging.

\subsection{SOA aging $-\mathrm{a}$ closer look}

In the following we present results from the second part of the experiments with the focus on the sensitivity to $\mathrm{OH}$ exposure (lights on/off) and the dependence of $\kappa$ and VFR on the particle diameter. Figure 9 shows two different types of low concentration AP experiments: HONO photolysis (green traces) and dark OH (TME) experiment (yellow traces) partly with additional lights on (No. 5 and 14, see Table 2). The periods with lights on are indicated by arrows. In experiment No. 5 (green) the lights were the only $\mathrm{OH}$ source, in experiment No. 14 the lights were turned on and off in addition to the dark OH (TME) source. Organic aerosol mass, atomic $\mathrm{O}: \mathrm{C}$ ratio (panel a and d) from the AMS and VFR as well as $\kappa$ (panel $\mathrm{b}$ and $\mathrm{c}$ ) are plotted against time after $\mathrm{OH}$ started. Dry diameters $\left(D_{0}\right)$ are presented in different symbols.

All TDMA data are size-specific and the size dependence of the measured hygroscopicity and volatility has not been discussed so far. In experiment No. 14 the smaller particles tend to have a higher $\kappa$ and lower VFR (higher volatility); this is not observed in experiment No. 5. The variation in $\kappa$ between different $D_{0}$ is typically less than \pm 0.01 (i.e., within uncertainty), in extreme cases up to 0.03 , when comparing $D_{0}=50 \mathrm{~nm}$ and $D_{0}=150 \mathrm{~nm}$. For all experiments, several sets of $D_{0}$ with overlapping repeats are selected in the TDMA to ensure sufficient signal and consistent measurement.

Using the volatility data from the V-TDMA for experiment No. 14 from 6-9 h after the $\mathrm{OH}$ exposure as input for an evaporation model (Riipinen et al., 2010) showed a positive size 
dependence in the diameter range $100-150 \mathrm{~nm}$ - due to different evaporation kinetics of particles with different diameters. For this calculation, we approximated the SOA with a single component aerosol with saturation concentration of $1.2 \mu \mathrm{g} \mathrm{m}^{-3}$ and a mass accommodation coefficient of unity, chosen to produce consistent results with the measured VFR at $100 \mathrm{~nm}$. The SOA was assumed otherwise to have similar properties as the theoretical AP SOA modeled in Riipinen et al. (2010). Although this is a rough approximation, we believe it to be sufficient for this purpose of simply demonstrating the size-dependence of the evaporation kinetics. The size dependence predicted by the model is a bit stronger (VFR ranging from 0.71 to 0.83 with diameters ranging from 100 to $150 \mathrm{~nm}$ ) than the one observed in our measurements (VFR from 0.71 to 0.75 ). This size dependence of the evaporation of the particles is similar to what would be expected based on dynamic evaporation calculations. It is therefore possible that the observed size dependence is rather due to kinetic effects than different chemical composition. However, the possibility of size dependent changes in the chemical composition cannot be completely ruled out either based on our data.

The two experiments No. 5 and 14 in Fig. 9 also illustrate well the interplay between the two periods of $\mathrm{OH}$ induced chemical aging on VFR. The start of $\mathrm{OH}$ induced chemical aging at time zero resulted in an abrupt decrease in VFR (Fig. 9b) while SOA mass increased as already discussed above. When $\mathrm{OH}$ production stopped (lights off in experiment No. 5) the VFR increased without significant mass gain similar to the ripening until $\mathrm{OH}$ started again (lights on in experiment No. 5). The VFR then stayed constant while again SOA mass slightly increased. This is an indication that again more volatile compounds are condensing compensating the aging effect by other processes. In case of the dark $\mathrm{OH}$ (TME) experiment (No. 14) turning lights on enhances the $\mathrm{OH}$ level and more SOA mass is produced. VFR does not decrease as expected but the increasing trend is stopped and VFR remains constant (best seen for small particles). This may indicate again that this ripening-like process is compensated by the condensation of volatile compounds. When lights are turned off after $4.6 \mathrm{~h}$ VFR starts to increase. Since further condensation is small now and SOA mass gain is not significant anymore, the non-condensational chemical aging processes become dominant again. Another lights on period after $6.6 \mathrm{~h}$ does somewhat slow down the increasing trend. This may be expected because at this time not much additional condensation was observed.

The effects on $\kappa$ are less pronounced. In general $\kappa$ (Fig. 9c) increased with $\mathrm{OH}$ exposure while without $\mathrm{OH}$, when lights were off (experiment No. 5, 2-4h) $\kappa$ decreased significantly by about $10 \%$. The O:C ratio correlates well with $\kappa$ and shows for the dark OH (TME) experiment an almost constant and slow increase to values of 0.48-0.5 (Fig. 9d). The increasing trend for the HONO photolysis experiment (from about 0.46 to 0.52 ) is less visible due to relatively high noise caused by the small organic mass concentration in this experiment. The $\mathrm{O}: \mathrm{C}$ ratio seems to be less sensitive to the lights on/off effects compared to VFR and $\kappa$. This has partly to do with the large noise of this parameter due to the low particle mass concentration in these low AP experiments.

\section{Summary and conclusions}

After validation and characterization of a new V/H-TDMA we measured SOA during 15 different aging experiments with 10 to $40 \mathrm{ppb} \alpha$-pinene (AP) within the MUCHACHAS campaign in the PSI smog chamber. The retrieved parameters VFR and $\kappa$ for volatility and hygroscopicity are sensitive indicators of changes in the SOA properties. We assume that the observed changes of physical properties are caused by chemical changes as a result of condensation, heterogeneous oxidation, condensed phase reactions and other processes. Two periods were discerned for each reaction period (ozonolysis and $\mathrm{OH}$ exposure), as seen in Figs. 1 and 6. During ozonolysis there is the $\mathrm{O}_{3}$ induced condensation period and after the AP had reacted the on-going chemical and physical changes were called ripening. The $\mathrm{OH}$ induced chemical aging was divided into two periods with and without substantial mass gain.

The first period $\left(\mathrm{O}_{3}\right.$ induced condensation) forms most of the SOA mass. The exposure of the SOA and gas mixture resulting from ozonolysis to $\mathrm{OH}$ radicals produced up to $50 \%$ additional SOA mass. The SOA added by $\mathrm{OH}$ exposure was highly volatile, more oxidized and of smaller molecular mass than the SOA from ozonolysis. Based on a simple two-compound model we estimate that this new SOA forming compounds have a VFR $<0.5$ at $70^{\circ} \mathrm{C}$. The same volatility behavior was also observed with a V-TDMA during MUCHACHAS experiments at the AIDA (Karlsruhe) and the SAPHIR (Jülich) chamber (Salo et al., 2011). Once this condensation period came to an end we still observed significant changes of the aerosol properties. The $\kappa$ range agrees well with the findings from other hygroscopicity studies for AP SOA (Petters and Kreidenweis, 2007; Duplissy et al., 2008).

Generally, VFR increased while $\kappa$ and O:C ratio remained constant. This process appears to be independent of exposure to $\mathrm{OH}$. After the end of the ozonolysis period, when most AP had reacted we also observed a steady evolution of the VFR and chemical changes in the AMS. We call this unknown process ripening of the aerosol. We hypothesize that this process is caused by relatively slow transformations of the condensed phase (this can include evaporation, oxidation, condensation cycles) which do not influence the SOA mass concentrations but do influence intensive physical and chemical properties (such as VFR, $\kappa, \mathrm{O}: \mathrm{C}$ ). We conclude that the organic aerosol is continuously evolving once the SOA mass has been formed. Qi et al. (2010) also observed a steady 
change of hygroscopicity, volatility and chemical signature in photooxidation experiments of AP and xylene over many hours.

There were no significant differences found between dark $\mathrm{OH}$ (induced by tetramethylethylene, TME) and light $\mathrm{OH}$ (induced by HONO) induced aging, and also high and low $\mathrm{NO}_{\mathrm{x}}$ conditions had virtually no influence on the physical properties.

The combination of the physical properties volatility and hygroscopicity with chemical information from AMS is a highly suitable approach to access the complex chemical processes during formation and aging of SOA. However, there are many different processes intertwined in the aging of SOA and difficult to separate. Thus more comprehensive studies are needed which are designed such that these different processes can be better disentangled and quantified. Such studies should include sophisticated chemical analysis of specific compounds in the aerosol phase combined with a quantification of the oligomer content.

Acknowledgements. The authors thank René Richter and Günther Wehrle for the great support and work on the V/H-TDMA instrument and various smog chamber issues. This work was supported by the IMBALANCE project of the Competence Center Environment and Sustainability of the ETH Domain (CCES), the EU project EUROCHAMP-2, as well as the Swiss National Science Foundation. PFD is grateful for postdoctoral research support from the US-NSF (IRFP \#0701013).

Edited by: V. F. McNeill

\section{References}

Aiken, A. C., DeCarlo, P. F., and Jimenez, J. L.: Elemental analysis of organic species with electron ionization highresolution mass spectrometry, Anal. Chem., 79, 8350-8358, doi:10.1021/ac071150w, 2007.

Aiken, A. C., Decarlo, P. F., Kroll, J. H., Worsnop, D. R., Huffman, J. A., Docherty, K. S., Ulbrich, I. M., Mohr, C., Kimmel, J. R., Sueper, D., Sun, Y., Zhang, Q., Trimborn, A., Northway, M., Ziemann, P. J., Canagaratna, M. R., Onasch, T. B., Alfarra, M. R., Prévôt, A. S. H., Dommen, J., Duplissy, J., Metzger, A., Baltensperger, U., and Jimenez, J. L.: O/C and OM/OC ratios of primary, secondary, and ambient organic aerosols with highresolution time-of-flight aerosol mass spectrometry, Environ. Sci. Technol., 42, 4478-4485, doi:10.1021/es703009q, 2008.

Alfarra, M. R., Paulsen, D., Gysel, M., Garforth, A. A., Dommen, J., Prévôt, A. S. H., Worsnop, D. R., Baltensperger, U., and Coe, H.: A mass spectrometric study of secondary organic aerosols formed from the photooxidation of anthropogenic and biogenic precursors in a reaction chamber, Atmos. Chem. Phys., 6, 52795293, doi:10.5194/acp-6-5279-2006, 2006.

An, W. J., Pathak, R. K., Lee, B. H., and Pandis, S. N.: Aerosol volatility measurement using an improved thermodenuder: Application to secondary organic aerosol, J. Aerosol Sci., 38, 305314, doi:10.1016/j.jaerosci.2006.12.002, 2007.
Baltensperger, U., Kalberer, M., Dommen, J., Paulsen, D., Alfarra, M. R., Coe, H., Fisseha, R., Gascho, A., Gysel, M., Nyeki, S., Sax, M., Steinbacher, M., Prévôt, A. S. H., Sjogren, S., Weingartner, E., and Zenobi, R.: Secondary organic aerosols from anthropogenic and biogenic precursors, Faraday Discuss., 130, 265-278, doi:10.1039/b417367h, 2005.

Barmet, P., Dommen, J., DeCarlo, P. F., Tritscher, T., Praplan, A. P., Platt, S. M., Prévôt, A. S. H., Donahue, N. M., and Baltensperger, U.: $\mathrm{OH}$ clock determination by proton transfer reaction mass spectrometry at an environmental chamber, Atmos. Meas. Tech. Discuss., submitted, 2011.

Burtscher, H., Baltensperger, U., Bukowiecki, N., Cohn, P., Huglin, C., Mohr, M., Matter, U., Nyeki, S., Schmatloch, V., Streit, N., and Weingartner, E.: Separation of volatile and nonvolatile aerosol fractions by thermodesorption: instrumental development and applications, J. Aerosol Sci., 32, 427-442, doi:10.1016/S0021-8502(00)00089-6, 2001.

Cappa, C. D., and Wilson, K. R.: Evolution of organic aerosol mass spectra upon heating: Implications for OA phase and partitioning behavior, Atmos. Chem. Phys., 11, 1895-1911, doi:10.5194/acp11-1895-2011, 2011.

Chang, R. Y. W., Slowik, J. G., Shantz, N. C., Vlasenko, A., Liggio, J., Sjostedt, S. J., Leaitch, W. R., and Abbatt, J. P. D.: The hygroscopicity parameter (kappa) of ambient organic aerosol at a field site subject to biogenic and anthropogenic influences: relationship to degree of aerosol oxidation, Atmos. Chem. Phys., 10, 5047-5064, doi:10.5194/acp-10-5047-2010, 2010.

DeCarlo, P. F., Kimmel, J. R., Trimborn, A., Northway, M. J., Jayne, J. T., Aiken, A. C., Gonin, M., Fuhrer, K., Horvath, T., Docherty, K. S., Worsnop, D. R., and Jimenez, J. L.: Field-deployable, high-resolution, time-of-flight aerosol mass spectrometer, Anal. Chem., 78, 8281-8289, doi:10.1021/ac061249n, 2006.

Donahue, N. M., Robinson, A. L., Stanier, C. O., and Pandis, S. N.: Coupled partitioning, dilution, and chemical aging of semivolatile organics, Environ. Sci. Technol., 40, 2635-2643, doi:10.1021/esO52297c, 2006.

Duplissy, J., Gysel, M., Alfarra, M. R., Dommen, J., Metzger, A., Prévôt, A. S. H., Weingartner, E., Laaksonen, A., Raatikainen, T., Good, N., Turner, S. F., McFiggans, G., and Baltensperger, U.: Cloud forming potential of secondary organic aerosol under near atmospheric conditions, Geophys. Res. Lett., 35, L03818, doi:10.1029/2007GL031075, 2008.

Duplissy, J., Gysel, M., Sjogren, S., Meyer, N., Good, N., Kammermann, L., Michaud, V., Weigel, R., Martins dos Santos, S., Gruening, C., Villani, P., Laj, P., Sellegri, K., Metzger, A., McFiggans, G. B., Wehrle, G., Richter, R., Dommen, J., Ristovski, Z., Baltensperger, U., and Weingartner, E.: Intercomparison study of six HTDMAs: results and recommendations, Atmos. Meas. Tech., 2, 363-378, doi:10.5194/amt-2-363-2009, 2009.

Duplissy, J., DeCarlo, P. F., Dommen, J., Alfarra, M. R., Metzger, A., Barmpadimos, I., Prévôt, A. S. H., Weingartner, E., Tritscher, T., Gysel, M., Aiken, A. C., Jimenez, J. L., Canagaratna, M. R., Worsnop, D. R., Collins, D. R., Tomlinson, J., and Baltensperger, U.: Relating hygroscopicity and composition of organic aerosol particulate matter, Atmos. Chem. Phys., 11, 1155-1165, doi:10.5194/acp-11-1155-2011, 2011.

Epstein, S. A., and Donahue, N. M.: The kinetics of tetramethylethene ozonolysis: Decomposition of the primary ozonide and subsequent product formation in the condensed phase, J. 
Phys. Chem. A, 112, 13535-13541, doi:10.1021/jp807682y, 2008.

Gysel, M., McFiggans, G. B., and Coe, H.: Inversion of tandem differential mobility analyser (TDMA) measurements, J. Aerosol Sci., 40, 134-151, doi:10.1016/j.jaerosci.2008.07.013, 2009.

Hallquist, M., Wenger, J. C., Baltensperger, U., Rudich, Y., Simpson, D., Claeys, M., Dommen, J., Donahue, N. M., George, C., Goldstein, A. H., Hamilton, J. F., Herrmann, H., Hoffmann, T., Iinuma, Y., Jang, M., Jenkin, M. E., Jimenez, J. L., KiendlerScharr, A., Maenhaut, W., McFiggans, G., Mentel, T. F., Monod, A., Prévôt, A. S. H., Seinfeld, J. H., Surratt, J. D., Szmigielski, R., and Wildt, J.: The formation, properties and impact of secondary organic aerosol: current and emerging issues, Atmos. Chem. Phys., 9, 5155-5236, doi:10.5194/acp-9-5155-2009, 2009.

Hodzic, A., Jimenez, J. L., Madronich, S., Canagaratna, M. R., DeCarlo, P. F., Kleinman, L., and Fast, J.: Potential contribution of semi-volatile and intermediate volatility primary organic compounds to secondary organic aerosol in the Mexico City region, Atmos. Chem. Phys., 10, 5491-5514, doi:10.5194/acp-10-54912010, 2010.

Huffman, J. A., Ziemann, P. J., Jayne, J. T., Worsnop, D. R., and Jimenez, J. L.: Development and characterization of a fast-stepping/scanning thermodenuder for chemically-resolved aerosol volatility measurements, Aerosol Sci. Technol., 42, 395407, doi:10.1080/02786820802104981, 2008.

Huffman, J. A., Docherty, K. S., Mohr, C., Cubison, M. J., Ulbrich, I. M., Ziemann, P. J., Onasch, T. B., and Jimenez, J. L. Chemically-resolved volatility measurements of organic aerosol from different sources, Environ. Sci. Technol., 43, 5351-5357, doi:10.1021/es803539d, 2009.

Jimenez, J. L., Canagaratna, M. R., Donahue, N. M., Prévôt, A. S. H., Zhang, Q., Kroll, J. H., DeCarlo, P. F., Allan, J. D., Coe, H., Ng, N. L., Aiken, A. C., Docherty, K. S., Ulbrich, I. M., Grieshop, A. P., Robinson, A. L., Duplissy, J., Smith, J. D., Wilson, K. R., Lanz, V. A., Hueglin, C., Sun, Y. L., Tian, J., Laaksonen, A., Raatikainen, T., Rautiainen, J., Vaattovaara, P., Ehn, M., Kulmala, M., Tomlinson, J. M., Collins, D. R., Cubison, M. J., Dunlea, E. J., Huffman, J. A., Onasch, T. B., Alfarra, M. R., Williams, P. I., Bower, K., Kondo, Y., Schneider, J., Drewnick, F., Borrmann, S., Weimer, S., Demeriian, K., Salcedo, D., Cottrell, L., Griffin, R., Takami, A., Miyoshi, T., Hatakeyama, S., Shimono, A., Sun, J. Y., Zhang, Y. M., Dzepina, K., Kimmel, J. R., Sueper, D., Jayne, J. T., Herndon, S. C., Trimborn, A. M., Williams, L. R., Wood, E. C., Middlebrook, A. M., Kolb, C. E., Baltensperger, U., and Worsnop, D. R.: Evolution of organic aerosols in the atmosphere, Science, 326, 1525-1529, doi:10.1126/science.1180353, 2009.

Jonsson, A. M., Hallquist, M., and Saathoff, H.: Volatility of secondary organic aerosols from the ozone initiated oxidation of alpha-pinene and limonene, J. Aerosol Sci., 38, 843-852, doi:10.1016/j.jaerosci.2007.06.008, 2007.

Juranyi, Z., Gysel, M., Duplissy, J., Weingartner, E., Tritscher, T., Dommen, J., Henning, S., Ziese, M., Kiselev, A., Stratmann, F., George, I., and Baltensperger, U.: Influence of gas-to-particle partitioning on the hygroscopic and droplet activation behaviour of alpha-pinene secondary organic aerosol, Phys. Chem. Chem. Phys., 11, 8091-8097, doi:10.1039/b904162a, 2009.

Kalberer, M., Paulsen, D., Sax, M., Steinbacher, M., Dommen, J.,
Prévôt, A. S. H., Fisseha, R., Weingartner, E., Frankevich, V., Zenobi, R., and Baltensperger, U.: Identification of polymers as major components of atmospheric organic aerosols, Science, 303, 1659-1662, doi:10.1126/science.1092185, 2004

Lindinger, W., Hansel, A., and Jordan, A.: On-line monitoring of volatile organic compounds at pptv levels by means of protontransfer-reaction mass spectrometry (PTR-MS) - Medical applications, food control and environmental research, Int. J. Mass Spectrom., 173, 191-241, doi:10.1016/S0168-1176(97)00281-4, 1998.

Lohmann, U. and Feichter, J.: Global indirect aerosol effects: a review, Atmos. Chem. Phys., 5, 715-737, doi:10.5194/acp-5-7152005, 2005.

Massoli, P., Lambe, A. T., Ahern, A. T., Williams, L. R., Ehn, M., Mikkila, J., Canagaratna, M. R., Brune, W. H., Onasch, T. B., Jayne, J. T., Petaja, T., Kulmala, M., Laaksonen, A., Kolb, C. E., Davidovits, P., and Worsnop, D. R.: Relationship between aerosol oxidation level and hygroscopic properties of laboratory generated secondary organic aerosol (SOA) particles, Geophys. Res. Lett., 37, L24801, doi:10.1029/2010g1045258, 2010.

Modini, R. L., Harris, B., and Ristovski, Z. D.: The organic fraction of bubble-generated, accumulation mode sea spray aerosol (SSA), Atmos. Chem. Phys., 10, 2867-2877, doi:10.5194/acp-97607-2009, 2010

Meyer, N. K., Duplissy, J., Gysel, M., Metzger, A., Dommen, J., Weingartner, E., Alfarra, M. R., Prévôt, A. S. H., Fletcher, C., Good, N., McFiggans, G., Jonsson, A. M., Hallquist, M., Baltensperger, U., and Ristovski, Z. D.: Analysis of the hygroscopic and volatile properties of ammonium sulphate seeded and unseeded SOA particles, Atmos. Chem. Phys., 9, 721-732, doi:10.5194/acp-9-721-2009, 2009.

Pankow, J. F.: An absorption-model of gas-particle partitioning involved in the formation of secondary organic aerosol, Atmos. Environ., 28, 189-193, doi:10.1016/1352-2310(94)900949, 1994a.

Pankow, J. F.: An absorption-model of gas-particle partitioning of organic-compounds in the atmosphere, Atmos. Environ., 28, 185-188, doi:10.1016/1352-2310(94)90093-0, 1994b.

Park, D., Kim, S., Choi, N. K., and Hwang, J.: Development and performance test of a thermo-denuder for separation of volatile matter from submicron aerosol particles, J. Aerosol Sci., 39, 1099-1108, doi:10.1016/j.jaerosei.2008.07.002, 2008

Pathak, R. K., Stanier, C. O., Donahue, N. M., and Pandis, S. N.: Ozonolysis of alpha-pinene at atmospherically relevant concentrations: Temperature dependence of aerosol mass fractions (yields), J. Geophys. Res.-Atmos., 112(8), D03201, doi:10.1029/2006jd007436, 2007.

Paulsen, D., Dommen, J., Kalberer, M., Prévôt, A. S. H., Richter, R., Sax, M., Steinbacher, M., Weingartner, E., and Baltensperger, U.: Secondary organic aerosol formation by irradiation of 1,3,5trimethylbenzene- $\mathrm{NO}_{\mathrm{x}}-\mathrm{H}_{2} \mathrm{O}$ in a new reaction chamber for atmospheric chemistry and physics, Environ. Sci. Technol., 39, 2668-2678, doi:10.1021/es0489137, 2005.

Petters, M. D., Kreidenweis, S. M., Snider, J. R., Koehler, K. A., Wang, Q., Prenni, A. J., and Demott, P. J.: Cloud droplet activation of polymerized organic aerosol, Tellus Ser. B-Chem. Phys. Meteorol., 58, 196-205, doi:10.1111/j.1600-0889.2006.00181.x, 2006.

Petters, M. D., and Kreidenweis, S. M.: A single parameter repre- 
sentation of hygroscopic growth and cloud condensation nucleus activity, Atmos. Chem. Phys., 7, 1961-1971, doi:10.5194/acp-71961-2007, 2007.

Petters, M. D., Wex, H., Carrico, C. M., Hallbauer, E., Massling, A., McMeeking, G. R., Poulain, L., Wu, Z., Kreidenweis, S. M., and Stratmann, F.: Towards closing the gap between hygroscopic growth and activation for secondary organic aerosol - Part 2: Theoretical approaches, Atmos. Chem. Phys., 9, 3999-4009, doi:10.5194/acp-9-3999-2009, 2009.

Prenni, A. J., Petters, M. D., Kreidenweis, S. M., DeMott, P. J., and Ziemann, P. J.: Cloud droplet activation of secondary organic aerosol, J. Geophys. Res.-Atmos., 112, D10223, doi:10.1029/2006JD007963, 2007.

Qi, L., Nakao, S., Malloy, Q., Warren, B., and Cocker, D. R.: Can secondary organic aerosol formed in an atmospheric simulation chamber continuously age?, Atmos. Environ., 44, 2990-2996, doi:10.1016/j.atmosenv.2010.05.020, 2010.

Rader, D. J., and McMurry, P. H.: Application of the tandem differential mobility analyzer to studies of droplet growth or evaporation, J. Aerosol Sci., 17, 771-787, doi:10.1016/00218502(86)90031-5, 1986.

Reinhardt, A., Emmenegger, C., Gerrits, B., Panse, C., Dommen, J., Baltensperger, U., Zenobi, R., and Kalberer, M.: Ultrahigh mass resolution and accurate mass measurements as a tool to characterize oligomers in secondary organic aerosols, Anal. Chem., 79, 4074-4082, doi:10.1021/ac062425v, 2007.

Riipinen, I., Pierce, J. R., Donahue, N. M., and Pandis, S. N.: Equilibration time scales of organic aerosol inside thermodenuders: Evaporation kinetics versus thermodynamics, Atmos. Environ., 44, 597-607, doi:10.1016/j.atmosenv.2009.11.022, 2010.

Robinson, A. L., Donahue, N. M., Shrivastava, M. K., Weitkamp, E. A., Sage, A. M., Grieshop, A. P., Lane, T. E., Pierce, J. R., and Pandis, S. N.: Rethinking organic aerosols: Semivolatile emissions and photochemical aging, Science, 315, 1259-1262, doi:10.1126/science.1133061, 2007.

Rudich, Y., Donahue, N. M., and Mentel, T. F.: Aging of organic aerosol: Bridging the gap between laboratory and field studies, Annu. Rev. Phys. Chem., 58, 321-352, doi:10.1146/annurev.physchem.58.032806.104432, 2007.

Salo, K., Hallquist, M., Jonsson, Å. M., Saathoff, H., Naumann, K.-H., Spindler, C., Tillmann, R., Fuchs, H., Bohn, B., Rubach, F., Mentel, Th. F., Müller, L., Reinnig, M., Hoffmann, T., and Donahue, N. M.: Volatility of secondary organic aerosol during $\mathrm{OH}$ radical induced ageing, Atmos. Chem. Phys., 11, 1105511067, doi:10.5194/acp-11-11055-2011, 2011.

Scheibel, H. G. and Porstendoerfer, J.: Generation of monodisperse Ag- and $\mathrm{NaCl}$-aerosol with particle diameters between 2 $\mathrm{nm}$ and $300 \mathrm{~nm}$, J. Aerosol Sci., 14, 113-126, doi:10.1016/00218502(83)90035-6, 1983.
Shilling, J. E., King, S. M., Mochida, M., and Martin, S. T.: Mass spectral evidence that small changes in composition caused by oxidative aging processes alter aerosol CCN properties, J. Phys. Chem. A, 111, 3358-3368, doi:10.1021/jp068822r, 2007.

Swietlicki, E., Hansson, H. C., Hameri, K., Svenningsson, B., Massling, A., McFiggans, G., McMurry, P. H., Petaja, T., Tunved, P., Gysel, M., Topping, D., Weingartner, E., Baltensperger, U., Rissler, J., Wiedensohler, A., and Kulmala, M.: Hygroscopic properties of submicrometer atmospheric aerosol particles measured with H-TDMA instruments in various environments - a review, Tellus Ser. B-Chem. Phys. Meteorol., 60, 432-469, doi:10.1111/j.1600-0889.2008.00350.x, 2008.

Taira, M. and Kanda, Y.: Continuous generation system for lowconcentration gaseous nitrous-acid, Anal. Chem., 62, 630-633, doi:10.1021/ac00205a018, 1990.

Vaden, T. D., Imre, D., Beranek, J., Shrivastava, M., and Zelenyuk, A.: Evaporation kinetics and phase of laboratory and ambient secondary organic aerosol, Proc. Natl. Acad. Sci. USA, 108, 2190-2195, doi:10.1073/pnas.1013391108, 2011.

Varutbangkul, V., Brechtel, F. J., Bahreini, R., Ng, N. L., Keywood, M. D., Kroll, J. H., Flagan, R. C., Seinfeld, J. H., Lee, A., and Goldstein, A. H.: Hygroscopicity of secondary organic aerosols formed by oxidation of cycloalkenes, monoterpenes, sesquiterpenes, and related compounds, Atmos. Chem. Phys., 6, 23672388, doi:10.5194/acp-6-2367-2006, 2006.

Villani, P., Picard, D., Marchand, N., and Laj, P.: Design and validation of a 6-volatility tandem differential mobility analyzer (VTDMA), Aerosol Sci. Technol., 41, 898-906, doi:10.1080/02786820701534593, 2007.

Volkamer, R., Jimenez, J. L., San Martini, F., Dzepina, K., Zhang, Q., Salcedo, D., Molina, L. T., Worsnop, D. R., and Molina, M. J.: Secondary organic aerosol formation from anthropogenic air pollution: Rapid and higher than expected, Geophys. Res. Lett., 33, L17811, doi:10.1029/2006g1026899, 2006.

Wehner, B., Philippin, S., and Wiedensohler, A.: Design and calibration of a thermodenuder with an improved heating unit to measure the size-dependent volatile fraction of aerosol particles, J. Aerosol Sci., 33, 1087-1093, doi:10.1016/S00218502(02)00056-3, 2002.

Wu, Z. J., Poulain, L., Wehner, B., Wiedensohler, A., and Herrmann, H.: Characterization of the volatile fraction of laboratory-generated aerosol particles by thermodenuder-aerosol mass spectrometer coupling experiments, J. Aerosol Sci., 40, 603-612, doi:10.1016/j.jaerosci.2009.03.007, 2009. 